\title{
Networks and Misallocation: Insurance, Migration, and the Rural-Urban Wage Gap *
}

\author{
Kaivan Munshi ${ }^{\dagger} \quad$ Mark Rosenzweig ${ }^{\ddagger}$
}

July 2014

\begin{abstract}
We provide an explanation for large spatial wage disparities and low male migration in India that is based on the trade-off between consumption-smoothing, provided by caste-based rural insurance networks, and the income-gains from migration. Our theory generates two key predictions, which we verify empirically: (i) relatively wealthy households within the caste who benefit less from the redistributive (surplus-maximizing) network will be more likely to have migrant members, and (ii) households facing greater rural income-risk (who benefit more from the insurance network) are less likely to have migrant members. Structural estimates of the model show that even small improvements in formal insurance decrease the spatial misallocation of labor by substantially increasing migration.
\end{abstract}

${ }^{*}$ We are very grateful to Andrew Foster for his help with the structural estimation and for many useful discussions that substantially improved the paper. Jiwon Choi and Scott Weiner provided outstanding research assistance. Viktoria Hnatkovskay and Amartya Lahiri graciously provided us with the NSS wage data. Research support from NICHD grant R01-HD046940 and NSF grant SES-0431827 is gratefully acknowledged.

${ }^{\dagger}$ University of Cambridge

${ }^{\ddagger}$ Yale University 


\section{Introduction}

The misallocation of resources is widely believed to explain a substantial proportion of the variation in productivity and income across countries. Past work has documented both differences in productivity across firms (e.g. Restuccia and Rogerson 2008, Hsieh and Klenow 2009) and the misallocation of resources across sectors; most notably the differences in (marginal) productivity between agriculture and non-agriculture (Caselli 2005, Restuccia, Yang, and Zhu 2008, Vollrath 2009, Gollin, Lagakos, and Waugh 2014). While this literature has devoted much attention to the relationship between misallocation, at the firm or sectoral level, and cross-country income differences (e.g. Parente and Prescott 1999, Lagos 2006, Buera and Shin 2013), relatively little is known about the determinants of the misallocation itself.

In India, the rural-urban wage gap, corrected for cost-of-living-differences, is greater than 25 percent and has remained large for decades, as we document in this paper. One explanation for this large wage gap is that underlying market failures prevent workers from taking advantage of arbitrage opportunities. A second explanation, based on a recent paper by Alwyn Young (2014) is that the large wage gap solely reflects differences in skill between rural and urban workers. In Young's framework, there is perfect inter-sectoral mobility and the size of the wage gap is completely determined by differences in the skillintensity of production between the rural and urban sectors. It follows that a country with an exceptionally large wage gap, such as India, will be characterized by an exceptionally large flow of workers sorting on skill. In contrast with this prediction, and indicative of misallocation, we will see that internal migration is very low in India, both in absolute terms as well as relative to other countries of comparable size and level of economic development.

The rural-urban wage divide is not the only symptom of spatial labor misallocation in India. Rural wages differ substantially across Indian villages and districts, and studies of rural wage determination have shown that shifts in local supply and demand affect local wages, which would not be true if labor were spatially mobile (Rosenzweig 1978, Jayachandran 2006). It is not that spatial mobility in India is generally low. Almost all women leave their native village upon marriage (Rosenzweig and Stark 1990). The question is why rural male workers have not taken advantage of the substantial economic opportunities associated with spatial wage differentials in India to move permanently to the city.

The explanation we propose, in the spirit of Banerjee and Newman (1998), is based on a combination of well-functioning rural insurance networks and the absence of formal insurance, which includes government safety nets and private credit. In rural India, informal insurance networks are organized along caste lines. The basic marriage rule in India, which recent genetic evidence indicates has been binding for 1900 years, is that no individual 
is permitted to marry outside the sub-caste or jati (for expositional convenience we will use the term caste, interchangeably with sub-caste, throughout the paper). Frequent social interactions and close ties within the caste, which consists of thousands of households and spans a wide area covering many villages, support very connected and exceptionally extensive insurance networks (Caldwell, Reddy, and Caldwell 1986, Mazzocco and Saini 2012).

Households with migrant members will have reduced access to rural caste networks for two reasons. First, migrants cannot be as easily punished by the network, and their family back home in the village now has superior outside options (in the event that the household is excluded from the network). It follows that households with migrants cannot credibly commit to honoring their future obligations at the same level as households without migrants. Second, an information problem arises if the migrant's income cannot be observed. If the household is treated as a collective unit by the network, it always has an incentive to misreport its urban income so that transfers flow in its direction. If the resulting loss in network insurance from migration exceeds the income gain, then large wage gaps could persist without generating a flow of workers to higher-wage areas. Just as financial frictions distort the allocation of capital across firms in Buerra, Kaboski, and Shin (2012), the absence of formal insurance distorts the allocation of labor across sectors in the model that we develop below. This distortion is paradoxically amplified when the informal insurance networks work exceptionally well because rural households then have more to lose by sending their members to the city.

One way to circumvent these restrictions on mobility would be for members of the rural community to move to the city (or another rural location) as a group. Members of the group could monitor each other and enforce collective punishments, solving the information and commitment problems described above. They would also help each other find jobs at the destination. The history of industrialization and urbanization in India is indeed characterized by the formation and the evolution of caste-based urban networks, sometimes over multiple generations (Morris 1965, Chandravarkar 1994, Munshi and Rosenzweig 2006). A limitation of this strategy is that a sufficiently large (common) shock is needed to jump-start the new network at the destination, and such opportunities occur relatively infrequently (Munshi 2011). Thus, while members of a relatively small number of castes with (fortuitously) well established destination networks can move with ease, most potential migrants will lack the social support they need to move.

A second strategy to reduce the information and enforcement problems that restrict mobility is to migrate temporarily. Seasonal temporary migration has, in fact, been increasing over time in India (Morten 2012). The principal limitation of the temporary migration strategy is that it will not fill the large number of jobs in developing economies in which 
there is firm-specific or task-specific learning and where firms will set permanent wage contracts. ${ }^{1}$

Both strategies discussed above will be used by rural households and castes to facilitate mobility. However, the central hypothesis of this paper is that men will nevertheless be discouraged from moving permanently and the labor market will not clear, giving rise to the large spatial wage gaps and the low male permanent migration rates that motivate our analysis. ${ }^{2}$ Previous studies have also made the connection between insurance networks and migration in India. Rosenzweig and Stark (1990) show that marital migration by women extends network ties beyond village boundaries. Morten (2012) links opportunities for temporary migration to the performance of rural networks. Both of these studies take participation in the network as given, whereas we hypothesize that permanent male migration can result in the exclusion of entire households from the network. The simplest test of the hypothesis that this potential loss in network services restricts mobility in India would be to compare migration rates in populations with and without caste-based insurance. This exercise is infeasible, given the pervasiveness of caste networks. What we do instead is to look within the caste and theoretically identify which households benefit less (more) from caste-based insurance. We then proceed to test whether it is precisely those households that are more (less) likely to have migrant members.

When an insurance network is active, the income generated by its members is pooled in each period and then distributed on the basis of a pre-specified sharing rule. This smoothes consumption over time, making risk-averse individuals better off. The literature on mutual insurance is concerned with ex post risk sharing, taking the size of the network and the sharing rule as given. ${ }^{3}$ To derive the connection between networks and permanent migration, however, it is necessary to take a step back and model the ex ante participation decision and the optimal design of the income sharing rule. In our framework, households can either remain in the village and participate in the insurance network or send one or more of their members to the city, increasing their income but losing the services of the

\footnotetext{
${ }^{1}$ Migrants being newcomers to the destination labor market need connections to find a job when they first arrive. Circular migration, in which migrants move back and forth between the origin and the destination, may thus be even more dependent on destination networks than permanent migration (Munshi 2003). As discussed above, this need for a network can substantially reduce the pool of potential migrants and overall mobility.

${ }^{2}$ While we provide a specific risk-based mechanism to explain large rural-urban wage gaps in India, the literature on international migration merely postulates the existence of "migration costs" to explain the persistence of global wage inequalities (e.g., Chiquiar and Hanson 2005, McKenzie and Rapoport 2010).

${ }^{3}$ With complete risk-sharing, the sharing rule is independent of the state of nature, generating simple statistical tests that have been implemented with data from numerous developing countries. The general result is that high levels of risk-sharing are sustained, but complete risk-sharing is rejected (e.g. Townsend 1994, Grimard 1997, Ligon 1998, Fafchamps and Lund 2003, Angelucci, De Georgi, and Rasul 2014). These empirical regularities have led, in turn, to a parallel line of research that characterizes and tests state (and history) dependent sharing rules under partial insurance (Coate and Ravallion 1993, Udry 1994, Ligon, Thomas, and Worrall 2002). The benchmark sharing-rule, in the initial period and when the participation constraint does not bind, continues to be exogenously determined in these models.
} 
network. The sharing rule that is chosen in equilibrium determines which households choose to stay.

With diminishing marginal utility, the total surplus generated by the insurance arrangement can be increased by redistributing income so that relatively poor households consume more than they earn on average. This gain from redistribution must be weighed against the cost to the members of the network from the accompanying decline in its size, since relatively wealthy households will now be more likely to leave and smaller networks are less able to smooth consumption. We are able to show, under reasonable conditions, that the income sharing rule will nevertheless be set so that there is some amount of redistribution in equilibrium. This implies that relatively wealthy households within their caste benefit less from the network and so will be more likely to have migrant members ceteris paribus, providing the first prediction of the theory. ${ }^{4}$

While women's migration at marriage diversifies the income of the network, migration by a male household member diversifies the household's income and so is typically assumed to lower the income-risk that the household faces (e.g., Lucas and Stark 1985). The implicit assumption in our framework is that in the Indian context, the loss in network insurance when an adult male from the household migrates dominates this gain from income diversification. It follows that households who face higher rural income-risk and who, therefore, benefit more from the network ceteris paribus, will be less likely to have male migrant members. This second prediction is especially useful in distinguishing our theory from alternative explanations for large rural-urban wage gaps and low migration in India. One alternative explanation for the lack of mobility is that individuals cannot enter the urban labor market without the support of a (caste) network at destination. There are also alternative explanations (discussed below) available for redistribution within the caste and the increased exit from the network by relatively wealthy households. However, none of these explanations imply that households facing greater rural income-risk should be less likely to have migrant members.

We begin the assessment of the theory by showing that there is substantial redistribution of income within castes, using data from the Indian ICRISAT panel surveys and from the most recent, 2006, round of the Rural Economic Development Survey (REDS), a nationally

\footnotetext{
${ }^{4}$ Our analysis is related, yet distinct in important respects, from Abramitzky (2008) who studies redistribution and exit in Israeli kibbutzim. For an exogenously determined (equal) income-sharing rule, he shows that exit rates are decreasing in communal wealth (which is forfeited upon exit) and that those with superior outside options are more likely to leave. In our model, the wealthy do not have superior outside options, wealth is private and is not forfeited, and the decision to participate and the income-sharing rule are endogenously and jointly determined. In a second model, Abramitzky uses diminishing marginal utility, as we do, to motivate redistribution. However, the sharing-rule is chosen such that there is no ex post exit once individuals' abilities and outside options are revealed. Genicot and Ray (2003), in contrast, endogenize the size of the risk-sharing arrangement, but assume that all individuals are ex ante identical, which implies an equal sharing-rule by construction. Our model endogenizes both the size of the network (and complementary migration) as well as the sharing rule, in a framework with heterogeneous households that builds naturally on existing models of ex post risk sharing.
} 
representative survey of rural Indian households that has been administered by the National Council of Applied Economic Research at multiple points in time over the past four decades. Following up on this result, we show (using data from a census of villages covered in the 2006 REDS) that relatively wealthy households within their caste are significantly more likely to report that one or more adult male members have permanently left the village. ${ }^{5}$ The literature on migrant selection; e.g., McKenzie and Rapaport (2010), Munshi (2011), indicates that migrant networks at destination support the movement of weaker - less able, less educated, less wealthy - individuals. In our analysis, insurance networks at the origin disproportionately discourage the movement of (relatively) less wealthy individuals. Highlighting the role that rural income-risk plays in the migration decision, we also find that households with a higher predicted coefficient of variation in their (rural) income - who benefit more from the rural insurance network - are less likely to have migrant members. ${ }^{6}$

Having found evidence consistent with the theory, we proceed to estimate the structural parameters of the model. Migration and the income-sharing rule are determined endogenously in the model. Our estimates of the income-sharing rule indicate that there is substantial redistribution within the caste, consistent with the descriptive evidence and the tests of the theory. Counter-factual simulations that quantify the effect of formal insurance on migration, leaving the rural insurance network in place, indicate that a 50 percent improvement in risk-sharing for households with migrant members (which is still some way from full risk-sharing) would more than double the migration rate. In contrast, (nearly) halving the rural-urban wage gap, from 18 percent to 10 percent, without any change in formal insurance, would reduce migration by just one percentage point.

\section{Descriptive Evidence}

This section begins by documenting the exceptionally large rural-urban wage gap in India and its exceptionally low migration rates. We subsequently describe the role played by rural caste networks in providing insurance for their members. The model developed in the next section is based on the premise that migration is accompanied by a loss in these network services, connecting rural caste networks to the low mobility, and accompanying labor misallocation, we have documented. This connection will be subjected to greater

\footnotetext{
${ }^{5}$ We subject this result to robustness tests that (i) use alternative measures of income and independent data sets, and (ii) that examine the relationship between the household's relative wealth and its participation in the caste-based insurance network. The latter test allows us to verify a key assumption of our model, and that of Banerjee and Newman (1998), which is that migration should be associated with a loss in network services.

${ }^{6} \mathrm{We}$ assume in the model that entire households do not migrate, consistent with evidence provided below, and that households with migrant members are treated by the network as a single collective unit. If entire households did migrate, or if individual migrants and the family members they left behind were treated independently by the network, then we would expect rural income-risk to be positively associated with migration.
} 
scrutiny in the empirical analysis that completes the paper.

\subsection{Rural-Urban Wage Gaps and Migration}

An important indicator of spatial immobility is the rural-urban wage gap. To measure the rural-urban wage gap in India we use the Government of India's $61^{\text {st }}$ National Sample Survey (NSS) covering the period July 2004-June 2005. Schedule 10 provides, for a given week during the survey period, the total number of days each person worked and, for workers classified as regular salaried employees or casual wage laborers, their wage and salary earnings both in cash and in kind. Based on this information, we computed a daily wage for each rural and urban worker. ${ }^{7}$ Column 1 of Table 1 reports the mean of these wages for rural and urban workers with less than primary education. We focus on this group to avoid the confounding effects of differences in the returns to education in rural and urban labor markets. Workers with little education will perform similar - menial - tasks in both markets, and so wage gaps for them can be interpreted as an arbitrage opportunity. The gap that we compute is very large - the urban wage is over 47 percent higher than the rural wage. As a basis for comparison, Figure 1 provides the percentage rural-urban wage gap in two large developing countries - China and Indonesia - computed from the 2005 Chinese mini Census and the Indonesia Family Life Survey (IFLS) 4 (2007), respectively. ${ }^{8}$ As can be seen, the wage gap for India, at over 45 percent, is much higher than the corresponding gap for the other two countries, which is about 10 percent.

One reason that urban wages are higher than rural wages is that the cost of living may differ across rural and urban areas. If the same bundle of goods consumed in urban areas costs more in rural areas, then the wage gap in Column 1 of Table 1 may overstate the real gain in earnings from migration. To adjust the wages for purchasing parity, we used the consumption information provided in Schedule 1.0 from the same NSS. Schedule 1.0 provides the value and quantity for durable and non-durable goods consumed by rural and urban households, enabling the computation of rural and urban unit prices. Table 1, Column 2 reports the urban wage deflated by the Laspeyres index (rural or origin base) and thus the real rural-urban wage gap. The PPP-adjusted urban wage is the nominal urban wage, multiplied by the value of the consumption bundle of rural households whose heads have less than primary education and then divided by the value of the same bundle based on urban prices. As can be seen, while this correction for standard of living substantially cuts the earnings advantage from shifting from rural to urban employment, there is still a

\footnotetext{
${ }^{7}$ The NSS, as do other Indian data sets, defines the urban population to include residents of cities and towns that exceed a population-size threshold. This threshold has changed over time, as discussed below.

${ }^{8}$ The wage for Indonesia is the hourly wage based on payments and wage work in the week preceding the survey for male wage workers aged 25-49 with less than primary school completion. Forty-eight percent of rural male workers were in that schooling category. The cross-sectional weights with attrition were used to compute the urban and rural means. The hourly wage for China is also for men aged 25-49 in the same educational category.
} 
real wage gap of over 27 percent. To assess the sensitivity of our results to the choice of consumption bundle, we used the corresponding urban consumption bundle, appropriately priced for rural and urban areas, to deflate the nominal urban wage. Using this destinationbased deflator (the Paasche index), the real wage-gap is even higher, at over 35 percent. $^{9}$

It is possible that the 2004-5 year was peculiar. To gage how the real wage gap has changed over time in India we use the nominal rural and urban wages estimated from the NSS rounds for 1983-4, 1993-4, 1999-2000, 2004-5, and 2009-10 by Hnatkovskay and Lahiri (2013) to compute the real urban and rural wages. First we apply our PPP correction to the urban wage series using the rural consumption bundle and unit prices from the 2004-5 NSS. We then apply the agricultural-worker CPI series and the industrial-worker CPI series to the PPP-adjusted rural and urban wage series, respectively, to obtain an inflation- and PPP-adjusted real wage series. Appendix Table A1 provides the nominal wages, the CPI figures, and the deflated wages by year for rural and urban workers. Figure 2 plots the movements in these wages over time. As can be seen, the real wage gap in 2004-5 actually underestimates the average wage gap over the period 1983-2009. After a sharp decline between 1999 and 2004, the wage gap remains stable from 2004-5 through 2009-10 at over 20 percent.

The change in the wage gap between 1999 and 2004 has two potential causes - a change in the definition of "urban" and the general-equilibrium effect of increased rural-to-urban migration. Hnatkovskay and Lahiri conclude that almost all of the change in the gap is due to the changing criteria for urbanization. By reclassifying some rural populations as urban, one would expect that the average urban wage would decrease but with possibly little effect on average rural wages. This is exactly what we see in Figure 2; when there is a decline in the wage gap, it is almost wholly due to a sharp urban wage decline. If the decline in the wage gap was due to rural-urban migration, then urban wages would decline and rural wages would increase. To provide additional support for the claim that the decline in the wage gap between 1999 and 2004 is not being driven by migration, we report migration rates based on decadal population censuses over the 1961-2001 period. Following Foster and Rosenzweig (2008), migration rates are computed for the cohort of

\footnotetext{
${ }^{9}$ As originally pointed out in Harris and Todaro (1970), migration responds to the expected wage; that is, the potential migrant takes into account the probability of employment. Although in that article the emphasis was on unemployment in urban areas, unemployment in rural areas potentially matters as well. The NSS elicited, in Schedule 10, information on employment and unemployment in the past year for all workers. The survey provides for each worker the number of months without work and whether, if without work, the worker made any efforts to get work on some or most days. From this information we computed the fraction of the year a worker was employed and/or unemployed for both rural and urban workers. Interestingly, but perhaps unsurprisingly given the seasonality of agriculture, non-employment and unemployment rates are higher in rural than in urban areas. We weighted real wages (where the nominal urban wage is deflated using the rural consumption bundle) by the rate of employment (fraction of the year employed) and by the fraction of days not unemployed, respectively. The expected earnings gain from migration using these figures is higher than the employment-unadjusted real wage-gap (Column 2), lying between 32 percent and 35 percent.
} 
males aged 15-24 (who are most likely to move for work) within each decade by comparing their numbers, residing permanently in rural and urban areas, at the beginning and the end of the decade. ${ }^{10}$ These migration rates are plotted in Figure 3, where no spike in migration is visible in the 1991-2001 period. Despite the persistently large (real) wage-gaps that we have documented, rural-urban migration in India has remained low for decades, reaching a maximum of 5.4 percent in the earliest period and dropping below 4 percent in recent decades. ${ }^{11}$

It is possible that the wage gap we quantify (conditional on education) merely reflects sorting on unobserved skill, and a large difference in the skill-intensities of production between rural and urban areas of India, as suggested by Young's (2014) model. We do not think sorting on skill explains the large wage gap in India. First, agriculture became more skill-intensive as a result of the Green Revolution in many parts of India starting in the 1970s and prior to the economic reforms of the 1990s (Foster and Rosenzweig 1995). Young's model would predict that the wage gap would therefore have declined in that period. It did not. Second, Young's model implies that migration rates from rural to urban and from urban to rural areas should both be high where wage gaps are high to achieve the appropriate mix of skills in both sectors. But in India, both urban and rural out-migration rates are low. An independent measure of migration can be constructed from the nationally representative India Human Development Survey (IHDS) conducted in 2005, which covers both rural and urban areas. The survey provides information on the number of years that each sampled household has been residing in the current location. We assume that a household has in-migrated if it has resided in that location for less than 10 years. Based on this definition, and restricting attention to households with male heads aged 25-49, the IHDS can be used to compute urban-rural and rural-urban migration rates. These statistics are 1.06 percent and 6.48 percent, respectively. Using the same definitions applied to the male sub-sample of the 2005 Indian DHS, the rates are 5.55 and 5.34 percent. There is thus no evidence that the exceptionally large wage gap in India is accompanied by a commensurate flow of workers, in either direction, refuting the counter-argument that

\footnotetext{
${ }^{10}$ This method requires that mortality rates are similar across urban and rural populations. In the age group 15-24, mortality is very low. The method also assumes that definitions of rural and urban remain constant across the decade. The urbanizing of the population by redefinition, as described above, will inflate the migration rates computed using the cohort method. The rates that are computed are thus likely to be upper bounds on true migration. The 2001 census indicates that movement due to marriage by women accounts for roughly 45 percent of all permanent migration in India, while employment, business, and the movement of entire families accounts for just 39 percent of migration (similar statistics are obtained in the 1991 round). We consequently focus on male out-migration when measuring the spatial mobility that is associated with the rural-urban wage gap.

${ }^{11}$ Although the detailed information needed to compute the migration rate from 2001 to 2011 is currently unavailable, provisional figures from the latest 2011 census indicate that the proportion of the population that is urban rose by only 3.8 percentage points between 2001 and 2011, to 31.6 percent (Ministry of Home Affairs, 2011).
} 
these gaps simply reflect differences in (unobserved) skill. ${ }^{12}$ Even with the DHS statistics, which are substantially higher than the corresponding IHDS statistics, migration rates are much lower in India than in countries of similar size and levels of economic development. For example, the 1997 Brazil DHS, which also includes a male sample, reports that urbanrural and rural-urban migration rates are 4.55 percent and 13.9 percent. The rural-urban migration rate, in particular, is more than twice as large as India.

India's unusually low mobility is also reflected in its urbanization rates. Figure 4 plots the percent of the adult population living in the city, and the change in this percentage over the 1975-2000 period, for four large developing countries: Indonesia, China, India, and Nigeria (UNDP 2002). Urbanization in all four countries was low to begin with in 1975 but India falls far behind the rest by 2000. Deshingkar and Anderson (2004) show that rates of urbanization in India are lower, by one full percentage point, than countries with similar levels of urbanization, and that the fraction of the population that is urban in India is 15 percent lower than in countries with comparable GDP per-capita. The exceptionally low mobility in India, despite the apparent benefit from moving to the city, demands an explanation. This is what we turn to next.

\subsection{Rural Insurance Networks}

In this section we show that transfers from caste members are important and preferred mechanisms through which consumption is smoothed in rural India. Much of the evidence is based on the 1982 and 1999 REDS rounds, which covered 259 villages in 16 major Indian states. Table 2 reports the percentage of households in the two survey rounds who gave or received caste transfers, which include gift amounts sent and received as well as loans originating from or provided to fellow caste members, in the year prior to each survey. The table shows that even in a single year, participation in the caste-based insurance arrangement is high - 25 percent of the households in the 1982 survey and 20 percent in the 1999 round. ${ }^{13}$ We would expect multiple households to support the receiving household when it is in need of support and consistent with this view, sending households contribute 57 percent of their annual income on average whereas the corresponding statistic for receiving households is $20-40$ percent. ${ }^{14}$

\footnotetext{
${ }^{12}$ Young (2014) reports balanced urban-rural and rural-urban migration rates above 20 percent in his sample of 65 countries. He uses DHS data and pools information on men and women. Men make up 10 percent of the sample. This is evidently unsatisfactory for India where 88 percent of women move outside their village when they marry (IHDS 2005). These women are not moving to clear the labor market, and the same problem arises in all other patrilocal societies in his sample. This is why we focus on male migrants in the discussion above.

${ }^{13}$ The statistics in Table 2 are weighted using sample weights and thus are population statistics.

${ }^{14}$ Some of these differences arise because sending households have higher income on average than receiving households, indicative of redistribution within the the caste that will play an important role in the discussion that follows. Nevertheless, it is easy to verify that the amount sent per household is less than the amount received.
} 
A variety of financial instruments are used to smooth consumption within the caste, with caste loans accounting for just 23 percent of all within-caste transfers by value. Nevertheless, the 1982 survey data in Table 3 indicate that although banks are the dominant source of rural credit, accounting for 64.6 percent of all loans by value, caste members are the dominant source of informal loans, making up 13.9 percent of the total value of loans received by households in the year prior to the survey. ${ }^{15}$ This is more than the amount households obtained from moneylenders (7.9 percent), friends (7.8 percent), and employers (5.6 percent). Table 3 reports the proportion of loans in value terms both by source and purpose. As can be seen, caste loans are disproportionately used to cover consumption expenses and for meeting contingencies such as illness and marriage. For example, although loans from caste members were 14 percent of all loans in value, they were 23 and 43 percent, respectively, of the value of all consumption and contingency loans. ${ }^{16}$ In contrast, bank loans are by far the dominant source of finance for investment and operating expenses, but account for just 25 percent and 28 percent of loans received for consumption expenses and contingencies.

Are the statistics in Table 3, representing the rural population of India in 1982, comparable to the current period? Columns 6-10 of Table 3 describe loans by source and purpose using the 2005 IHDS. This survey, conducted on a representative sample of rural households throughout the country, reports loans received over the five years preceding the survey by source. Unfortunately the survey does not use caste-group as a category, although it does identify loans from relatives, which we will assume are within-caste loans. Although some caste loans will now be assigned to other categories (if they are provided by caste members not directly related to the recipient), the basic patterns reported from the 1982 survey round in Columns 1-5 remain unchanged. Loans from relatives, make up 9 percent of all loans by value, more than both friends and employers. Looking across purposes, we see once again that informal caste loans are most useful in smoothing consumption and meeting contingencies. Overall, lending patterns have remained fairly constant over the two decades covered in Table $3 .^{17}$

We argue in this paper that caste networks restrict mobility because comparable arrangements are unavailable, particularly for smoothing consumption and meeting contingencies. Table 4 shows that loan terms are substantially more favorable for caste loans on

\footnotetext{
${ }^{15}$ We restrict attention to the 1982 survey because the classification of activities that loans are used for is much coarser in 1999; in particular, consumption expenses do not appear as a separate category.

${ }^{16}$ Caldwell, Reddy and Caldwell (1986) surveyed nine villages in South India after a two-year drought and found that nearly half $(46 \%)$ of the sampled households had taken consumption loans during the drought. The sources of these loans (by value) were government banks $(18 \%)$, moneylenders, landlord, employer $(28 \%)$, relatives and members of the same caste community $(54 \%)$, emphasizing the importance of caste loans for smoothing consumption.

${ }^{17}$ NGO's and credit groups, which have received a great deal of attention in the economics literature in recent years are included in the "Other" category in the IHDS. However, these sources together account for less than 2.1 percent of all loans by value received by rural households.
} 
average. It is quite striking that of the caste loans received in the year prior to the 1982 survey, 20 percent by value required no interest payment and no collateral. The corresponding statistic for the alternative sources of credit was close to zero, except for loans from friends where 4 percent of the loans were received on similarly favorable terms. The IHDS does not provide information on collateral but does report whether a loan was interest-free. We see in Table 4, Column 5 that caste (extended family) loans are substantially more likely to be interest-free than loans from other sources, matching the corresponding statistics from the 1982 REDS in Column $1 .^{18}$

Tables 3 and 4 establish that loans from caste members are important for smoothing consumption and meeting contingencies, and continue to be advantageous to borrowers compared with loans from major alternative sources of finance in rural India. It is important to reiterate that these caste loans account for a small fraction of all within-caste transfers by value. The cost of losing the services of the network is evidently substantial and may explain why individuals continue to marry within their sub-caste, which is a prerequisite for membership in the caste network, today.

Figure 5 reports rates of out-marriage (i.e. marriage between members of different castes) in rural India for the children and siblings of household heads over the 1950-1999 period, based on retrospective information collected in the 1999 REDS round. Out-marriage is just above 5 percent of all marriages, closely matching other sample surveys conducted in urban and rural India (IHDS 2005, Munshi and Rosenzweig 2006, Luke and Munshi 2011), and has remained stable over time. Recent genetic evidence indicates that binding restrictions on out-marriage were put in place 1900 years ago and that the Indian population today consists of 4,635 distinct genetic groups (Moorjani et al. 2013). ${ }^{19}$ These groups consist of thousands of households. Marital endogamy, together with the fact that women typically marry outside their natal village, allows caste networks to span wide areas, while maintaining their connectedness. This connectedness across villages is complemented by strong local ties, which arise as a consequence of the spatial segregation by caste within villages. Households that renege on their obligations will thus be punished locally (in the neighborhood) and in the wider caste community. Information will also flow very smoothly through this inter-linked community. The analysis that follows examines the effect of these exceptionally well-functioning caste networks on mobility and the rural-urban wage gap.

\footnotetext{
${ }^{18}$ Regression results with 1982 REDS data, reported in Table A2, indicate that caste loans are significantly more likely to be interest-free than loans from banks, employers, and moneylenders. They are also significantly more likely to be collateral-free than loans from banks.

${ }^{19}$ These genetic groups are not restricted to the Hindu population. Muslims marry within biradaris and Christians continue to marry within their original (pre-conversion) sub-castes or jatis. In our data set, Muslim households report their biradari and Christian households report their jati.
} 


\section{The Theory}

The model we develop in this section describes how the existence of well-functioning rural insurance networks can lead to low migration. The theoretical structure we develop will be taken to the data, allowing us to quantify the magnitude of the mobility restrictions. It will also be used to generate testable predictions that distinguish our theory from alternative explanations for the low mobility in India.

\subsection{Income, Preferences, and Risk-Sharing}

The basic decision-making unit is the household, which consists of multiple earners. The household belongs to a community within which all its social activities take place. Each household derives income from its local activities. Income varies independently across households in the community and over time. In addition, one or more members of the household receive a job opportunity in the city. The key decision is whether or not to send them to the city.

We assume that the household has logarithmic preferences. This allows us to express the expected utility from consumption, $C$, as an additively separable function of mean consumption, $M$, and normalized risk, $R \equiv V / M^{2}$, where $V$ is the variance of consumption. ${ }^{20}$

$$
E U(C)=\log (M)-\frac{1}{2} \frac{V}{M^{2}} .
$$

Rural incomes vary over time and so risk-averse households benefit from a communitybased insurance network to smooth their consumption. Because our interest is in the ex ante decision to participate in the rural insurance network, we assume that complete risksharing can be maintained ex post (once the arrangement has formed). The advantage of this assumption is that it allows us to derive closed-form solutions for the mean and variance of consumption with insurance that lead, in turn, to a simple migration decisionrule. This simplifies the theoretical analysis and later allows us to estimate a parsimonious structural model. This assumption is, moreover, broadly consistent with evidence from all over the developing world, including India, documenting extremely high levels of ex post risk-sharing.

\footnotetext{
${ }^{20}$ Evaluating log-consumption at mean consumption, $M$, and ignoring higher-order terms,

$$
\begin{gathered}
\log (C)=\log (M)+\frac{(C-M)}{M}-\frac{(C-M)^{2}}{2 M^{2}} . \\
E \operatorname{Elog}(C)=\log (M)-\frac{1}{2} \frac{V}{M^{2}} .
\end{gathered}
$$

For the Taylor expansion to be valid, with CRRA preferences, consumption must lie in the range $[0,2 M]$. This implies that its coefficient of variation must be less than 0.31 . The panel data that we use, described below, satisfies this condition for 90 percent of households with food consumption and 70 percent of households with overall consumption (which includes durables).
} 
The ex post commitment that is needed to support these high levels of risk-sharing is maintained by social sanctions, which take the form of exclusion from social interactions within the community when a participating household reneges on its obligations. These sanctions are less effective when someone from the household has migrated to the city. ${ }^{21}$ With full risk-sharing, the household is either in the network, receiving a fixed fraction of the income generated by the membership in each state of the world, or out of the network. We assume that households with migrants cannot commit to reciprocating at the level needed for full-risk sharing and so will be excluded from the network.

Urban income is private information in our model, as discussed below. If a household with permanent migrants is included in the insurance network, it will have an incentive to over-report the value of its urban income ex ante, as a way of increasing its incomeshare. Once the network is in place, however, it will have an incentive to under-report its income realizations ex post, claiming a series of negative shocks, as a way of channelling transfers in its direction. Partial insurance, which ties transfers to income realizations, will reduce the cost to the network from this information problem, but it will not change the household's incentive to misreport its income. This "hidden income" problem is potentially more important than the commitment problem in explaining why households with migrants will be excluded from the network. Each household thus has two options. It can remain in the village and participate in the insurance network, benefiting from the accompanying reduction in the variance of its consumption, or it can send one or more of its members to the city and add to its income but forego the services of the rural network.

\subsection{The Participation Decision}

Let $M_{A}, V_{A}$ denote the mean and variance of the household's income (which is the same as its consumption in autarky) when all its members remain in the village. Denote the mean and variance of its consumption if it participates in the insurance network by $M_{I}$, $V_{I}$, respectively. If one or more members move to the city, its mean income will increase to $M_{A}(1+\tilde{\epsilon})$, where $\tilde{\epsilon}$ denotes the gain in income from urban wages net of any loss in rural income due to their departure. This gain in income must be traded off against the increased consumption-risk that the household will face. With network insurance, (normalized) consumption-risk is denoted by $R_{I} \equiv V_{I} / M_{I}^{2}$. When the household sends migrants to the city, it loses the services of the network and the corresponding risk is $\beta R_{A}$, where $R_{A} \equiv V_{A} / M_{A}^{2}$. The standard presumption is that the income diversification that accompanies migration will reduce the income-risk that the household faces. Then

\footnotetext{
${ }^{21}$ While the community could punish the remaining members of the household, this is not as effective as punishing all members. One potential solution to this commitment problem would be for the remaining members to separate themselves from the migrants. This is not a credible strategy, however, because unobserved remittances can continue to flow within the household. The remaining household members also have better outside options (through their urban connection) which reduces their ability to commit.
} 
$\beta<1$ even if a household with migrants has no alternative mechanism through which it can smooth its consumption. As formal (non-network) insurance becomes available, the risk-parameter $\beta$ will decline even further. However, we continue to assume that migration increases the consumption-risk that the household faces, $R_{I}<\beta R_{A}$. This is the wedge that restricts mobility and allows a wage gap to be sustained in our theory. Note that this key insight of our theory would apply with any model of ex post risk-sharing, as long as the reduced access to the network resulted in increased consumption-risk for households with migrants.

With logarithmic preferences, the household will thus choose to participate in the rural insurance network and remain in the village if

$$
\log \left(M_{I}\right)-\frac{1}{2} \frac{V_{I}}{M_{I}^{2}} \geq \log \left(M_{A}\right)-\frac{1}{2} \beta \frac{V_{A}}{M_{A}^{2}}+\epsilon
$$

where $\epsilon \equiv \log (1+\tilde{\epsilon}){ }^{22}$ Given the standard assumption in models of mutual insurance that there is no storage and no savings, full risk-sharing and log preferences imply that each household's consumption will be a fixed fraction of the total income, $\sum_{i} y_{i s}$, that is generated by the $N$ households in the insurance network in each state $s$ of the world. Because expected rural income is the same for all households and the income-gain from migration, $\epsilon$, is uncorrelated with rural income and is private information, total income will be distributed equally among the members of the network.

Taking expectations, or variances, over all states, the equal-sharing rule implies that

$$
\begin{aligned}
& M_{I}=E\left(\frac{1}{N} \sum_{i} y_{i s}\right)=\frac{1}{N}\left(N M_{A}\right)=M_{A} \\
& V_{I}=V\left(\frac{1}{N} \sum_{i} y_{i s}\right)=\frac{1}{N^{2}}\left(N V_{A}\right)=\frac{V_{A}}{N} .
\end{aligned}
$$

Mean consumption with insurance, $M_{I}$, is equal to mean consumption under autarky, $M_{A}$. However, the variance of consumption with insurance, $V_{I}$, is less than the variance of consumption under autarky, $V_{A}$, for $N \geq 2$.

\subsection{Equilibrium Participation}

Based on the decision rule specified by inequality (1), participation will depend on the gain from mutual insurance, $1 / 2 \beta R_{A}-1 / 2 R_{I}$, versus the income-gain from migration, which is $\epsilon$ since $\log \left(M_{I}\right)=\log \left(M_{A}\right)$. The key feature of equation (3) is that it implies that the gain from insurance depends on the endogenously-determined number of network participants, $N$, since $V_{I}$ and, thus, $R_{I}$, is decreasing in $N$.

\footnotetext{
${ }^{22}$ If the terms in inequality (1) describe per-period utility, then both sides of the inequality would be multiplied by $1 / 1-\delta$ for an infinitely-lived household with discount factor $\delta$. This would have no effect on the results that follow.
} 
Because the gain from insurance depends on the decisions of other households in the community, the number of network participants, $N$, is the solution to a fixed-point problem. To determine the fraction of the population that participates in equilibrium, we first derive the threshold $\epsilon_{I}$ at which the participation condition holds with equality. Let the $\epsilon$ distribution be characterized by the function $F(\epsilon)$. We then set the fraction of the community that participates, $F\left(\epsilon_{I}\right)$, to be equal to $N / P$,

$$
\frac{N}{P}=F(\Delta M+\Delta R),
$$

where $P$ is the population of the community, $\Delta M \equiv \log \left(M_{I}\right)-\log \left(M_{A}\right), \Delta R \equiv 1 / 2 \beta R_{A}-$ $1 / 2 R_{I} . \Delta R$ is a function of $N$ from equation (3) and so equilibrium participation, $N^{*}$, can be derived from equation (4).

We make the following assumptions about the distribution of $\epsilon$ : A1. The left support is equal to zero. This assumption implies that average income must increase with migration, highlighting the trade off between moving and staying. A2. The right support of the distribution is unbounded. A3. The density of the distribution, $f$, is decreasing in $\epsilon$. This assumption says that superior urban opportunities occur less frequently in the population. Given these distributional assumptions,

Lemma 1. Equilibrium participation is characterized by a unique fixed point, $N^{*} \in(0, P)$.

$\Delta M=0$ because $M_{I}=M_{A} . \Delta R>0$ by assumption. This implies, from assumption A1, that $F(\Delta M+\Delta R)>N / P$ at $N=0$. Assumption A2 implies that $F(\Delta M+\Delta R)<$ $N / P$ at $N=P . F(\Delta M+\Delta R)$ is increasing in $N$ because $R_{I}$ is decreasing in $N$ (hence, $\Delta R$ must be increasing in $N$ ). By a continuity argument, a fixed point $N^{*}$ at which equation (4) is satisfied must exist. We show in the Appendix that assumption A3 implies that $F(\Delta M+\Delta R)$ is strictly concave, ensuring that this fixed point is unique.

\subsection{Participation and Income-Sharing with Inequality}

We now characterize equilibrium participation and the income-sharing rule with heterogeneous rural incomes. By introducing this realistic feature of communities, we are able to derive an important implication of our theory, which is that relatively wealthy households within the community will be more likely to migrate. To derive the new equilibrium, we take advantage of the fact that the ratio of marginal utilities between any two households participating in the network must be the same in all states of the world with full risksharing. Dividing the community into $K$ income classes of equal size, $P_{k}$, this implies, given $\log$ preferences, that $C_{k s} / C_{K s}=\lambda_{k}$, where $C_{k s}, C_{K s}$ denote the consumption of households in income class $k$ and $K$ (the highest income class) in state $s$ of the world.

Aggregating over all households who choose to participate in the network $-N_{k}$ in each income class $k$ - each household in income class $k$ consumes a fraction $\lambda_{k} / \sum_{k} \lambda_{k} N_{k}$ of the 
total income, $\sum_{i} y_{i s}$, that is generated by the insurance network in each state of the world. Note that we normalize so that $\lambda_{K}$ equals one. Following the same steps as in equations (2) and (3), expressions for the mean and variance of consumption with insurance in each income class $k$ are derived as follows:

$$
M_{I k}=\left(\frac{\lambda_{k}}{\sum_{k} \lambda_{k} N_{k}}\right) \sum_{k} N_{k} M_{A k} \quad V_{I k}=\left(\frac{\lambda_{k}}{\sum_{k} \lambda_{k} N_{k}}\right)^{2} \sum_{k} N_{k} V_{A k} .
$$

Because total income is pooled with full risk-sharing, consumption in each income class is now a function of the number of participants, $N_{k}$, and the income-sharing rule, $\lambda_{k}$, in every income class. However, equations (5) imply that the normalized risk, $R_{I} \equiv V_{I k} / M_{I k}^{2}$ is the same for all income classes and is independent of $\lambda$,

$$
R_{I}=\frac{\sum_{k} N_{k} V_{A k}}{\left(\sum_{k} N_{k} M_{A k}\right)^{2}}
$$

Participation in the network continues to be derived as the solution to a fixed-point problem, but this problem must now be solved for each income class. Equilibrium participation will satisfy the following conditions, corresponding to equation (4), for each income class $k$ :

$$
\frac{N_{k}}{P_{k}}=F\left(\Delta M_{k}+\Delta R_{k}\right),
$$

where $\Delta M_{k} \equiv \log \left(M_{I k}\right)-\log \left(M_{A k}\right), \Delta R_{k} \equiv 1 / 2 \beta R_{A k}-1 / 2 R_{I}$.

If we knew the income-sharing rule, $\lambda_{k}$, we could substitute expressions from equations (5) and (6) in equation (7) to solve simultaneously for $N_{k}$ in all $K$ income classes. The more challenging problem that we face is that the sharing-rule $\lambda_{k}$ and participation $N_{k}$ must be derived simultaneously. To derive the sharing rule that is chosen by the community, we assume that its objective is to maximize the surplus that is generated by the insurance network. This surplus is the utility from participation in the network minus the utility in autarky, summed over all income classes. Within each income class, $k$, the total number of participants is determined by a threshold epsilon, $\epsilon_{I k}=\Delta M_{k}+\Delta R_{k}$. Households with epsilon greater than $\epsilon_{I k}$ would send members to the city regardless of whether or not the insurance network was in place. They can thus be ignored when computing the surplus generated by the network. If $\beta<1$, and given that $\epsilon>0$, households with epsilon less than $\epsilon_{I k}$ will always send members to the city when the network is absent. Total surplus can then be described by the expression,

$$
W=\sum_{k} P_{k} \int_{0}^{\epsilon_{I k}}\left\{\left[\log \left(M_{I k}\right)-\frac{1}{2} R_{I}\right]-\left[\log \left(M_{A k}\right)-\frac{1}{2} \beta R_{A k}+\epsilon\right]\right\} f(\epsilon) d \epsilon .
$$


Noting that $N_{k}=P_{k} \int_{0}^{\epsilon} f(\epsilon) d \epsilon$ and collecting terms, the surplus function reduces to ${ }^{23}$

$$
W=\sum_{k} N_{k} \epsilon_{I k}-P_{k} \int_{0}^{\epsilon_{I k}} \epsilon f(\epsilon) d \epsilon
$$

Equilibrium participation and the income-sharing rule can be jointly derived by maximizing $W$ with respect to $\lambda_{k}$, subject to the fixed point conditions in equations (7), after substituting in the expressions for $M_{I k}, R_{I}$ from equations (5) and (6). We now use this theoretical framework to identify which households benefit less (more) from the network and who should therefore be more (less) likely to have migrant members.

\subsection{Relative Wealth, Rural Risk, and Migration}

If participation in the network were fixed, the community could increase the surplus generated by the network by redistributing income from richer households to poorer households (given diminishing marginal utility). If households can select out of the network, however, the sharing-rule must be attentive to the possibility that increased exit by households who subsidize the rest of the network will make it smaller, reducing its ability to smooth consumption. We nevertheless obtain the following result.

Proposition 1. Some redistribution is socially optimal, which implies that (relatively) wealthy households in the community should ceteris paribus be more likely to have migrant members.

To derive this result in the Appendix, we consider the case with two income classes, $k \in\{L, H\}$, of equal size, $P_{L}=P_{H}$, where $M_{A H}>M_{A L}$. Recall that the threshold epsilon in each income class, $\epsilon_{I k}=\Delta M_{k}+\Delta R_{k}$ and that the number of participants, $N_{k}=P_{k} F\left(\epsilon_{I k}\right)$. To ensure that differences in participation across income classes do not arise for other reasons, we assume that $R_{A L}=R_{A H}$, which implies that $\Delta R_{L}=\Delta R_{H}$, and that the epsilon distribution, characterized by the $F$ function, is the same for both income classes. Without income redistribution, mean consumption equals mean income for each household and so $\Delta M_{L}=\Delta M_{H}=0$. It follows that participation and, hence, migration rates will be the same in both income classes without redistribution.

Denote the ratio of consumption between low-income and high-income households in each state of the world by $\lambda$. Without income redistribution, $\lambda$ is the ratio of mean-incomes of the two classes, $M_{A L} / M_{A H}$. With equal income-sharing, $\lambda$ is equal to one. In general, $\lambda \in\left[M_{A L} / M_{A H}, 1\right]$. The sharing-rule $\lambda^{*}$ that is chosen in equilibrium cannot be derived analytically. What we do instead is to focus on the (only) income-sharing rule without redistribution, $\lambda=M_{A L} / M_{A H}$. We show that an increase in $\lambda$, evaluated at that sharing

\footnotetext{
${ }^{23}$ If $\beta>1$, then there exists a threshold epsilon, $0<\epsilon_{A k}<\epsilon_{I k}$, below which households do not send migrants to the city even when the network is absent. The second term in square brackets in the preceding equation is then replaced by $\int_{o}^{\epsilon_{A k}} \log \left(M_{A k}\right)-1 / 2 \beta R_{A k}+\int_{\epsilon_{A k}}^{\epsilon_{I k}} \log \left(M_{A k}\right)-1 / 2 \beta R_{A k}+\epsilon$. We would then integrate from $\epsilon_{A k}$ to $\epsilon_{I k}$, rather than from zero to $\epsilon_{I k}$, in the equation below. This would not, however, change any of the results that follow.
} 
rule, unambiguously increases the surplus, even after accounting for the effect on participation. This implies that there must be some redistribution in equilibrium. Migration rates do not vary across income classes in the absence of redistribution, by construction. With redistribution, relatively wealthy households benefit less from the network and so are more likely to have migrant members.

The theory also has implications for how variation in rural income-risk affects migration and redistribution within the network. The decision rule specified in equation (1) indicates that the gain from network insurance, $\beta R_{A}-R_{I}$, is larger for a household facing greater rural income-risk, $R_{A}$. This implies that the threshold epsilon, $\epsilon_{I}$, above which it will send members to the city is larger, and so it is more likely to participate in the network. However, we must once again account for potential redistribution and its consequences for participation. In this case, redistribution will favor safe households at the expense of households facing greater income-risk. We are nevertheless able to derive the following general result.

Proposition 2. Households that face greater rural income-risk are ceteris paribus less likely to have migrant members.

This result is derived in the Appendix. Income-classes, $k \in\{L, H\}$, are now replaced by risk-classes, $k \in\{R, S\}$. where $R_{A R}>R_{A S}$. To rule out redistribution for other reasons, mean rural incomes are assumed to be the same in both risk-classes, $M_{A R}=M_{A S}$. The epsilon distribution is also assumed to be the same in both classes. Relabel $\lambda$ to be the ratio of consumption between high-risk and low-risk households in each state of the world. Without redistribution, $\lambda=M_{A R} / M_{A S}=1$. If the two risk-classes are of equal size, $P_{R}=P_{S}$, then the number of network participants will be greater in the risky class, $N_{R}>N_{S}$, because $\Delta M_{R}=\Delta M_{S}=0, \Delta R_{R}>\Delta R_{S}$. The benefit of redistribution is that a dollar taken from each participating risky household will be divided among a smaller number of safe households. At the same time, the number of households that benefit is smaller than the number who lose and this will be accounted for when computing the surplus. The effect of redistribution on overall participation, with its consequences for consumption-smoothing, must also be considered.

If there are net gains from redistribution, nevertheless, then $\lambda$ will decline. However, since the gains from redistribution arise because $N_{R}>N_{S}, \lambda$ must be bounded below at a level $\underline{\lambda}$ at which participation is the same in both risk classes; $\lambda \in[\underline{\lambda}, 1]$. To prove Proposition 2 we focus on the (only) income-sharing rule with equal participation, $\lambda=\underline{\lambda}$, and show that an increase in $\lambda$ evaluated at $\underline{\lambda}$, unambiguously increases the surplus. This implies that $\lambda^{*}>\underline{\lambda}$ and, hence, that households facing greater rural income-risk have higher participation rates in equilibrium even with redistribution. 


\section{Testing the Theory}

The theory generates three testable predictions: (i) income is redistributed in favor of poor households within the caste, (ii) relatively wealthy households who, therefore, benefit less from the insurance network should be more likely to have migrant members, and (iii) households facing greater rural income-risk who benefit more from the network should be less likely to have migrant members. These tests shed light on the central hypothesis that insurance provided by rural networks inhibits mobility. Additional tests validate the key assumption that permanent male migration is associated with a loss in network services. These results, taken together, can be used to distinguish between our explanation for large wage gaps and low migration in India and alternative explanations that do not require a role for rural insurance networks.

One explanation for low migration and large wage gaps in India is based on the existence of urban caste-based labor market networks. While the members of a relatively small number of castes with well-established urban networks will enjoy high wages in the city, most potential migrants moving independently will be shut out of the urban labor market. Past research; e.g. Munshi and Rosenzweig (2006), Munshi (2011), indicates that caste networks continue to be active in Indian cities. However, this does not preclude the coexistence of our theory, in which the loss in rural insurance reduces individual migration, with this alternative explanation in which migrants must move as a group, which results in lower overall mobility. Two distinguishing features of our theory are (i) that households facing greater rural income-risk are less likely to have migrant members, and (ii) that migration is associated with a loss in network services. ${ }^{24}$

There also can be alternative explanations for the first two predictions of our theory, but no alternative that we are aware of delivers all three predictions. For example, it is possible that communities provide other types of public goods financed by a progressive payment scheme, also resulting in redistribution and increased exit by relatively wealthy households. ${ }^{25}$ Moreover, there may be other reasons why higher incomes in the community are associated with lower out-migration. Neither of these theories would explain why households facing greater rural income-risk are less likely to have migrant members.

\subsection{Evidence on Redistribution within Castes}

We first empirically assess the extent of redistribution within castes. We begin with data from the 2005-2011 Indian ICRISAT panel survey, which provides information on household

\footnotetext{
${ }^{24}$ Another explanation for low mobility, as in the literature on kin-tax; e.g. Platteau (2000), is that caste networks tax migrants heavily. However, this would not explain why greater rural income-risk is associated with lower migration.

${ }^{25}$ Recent evidence from developing countries suggests that while payment schemes in rural communities are indeed redistributive, they are regressive rather than progressive (Olken and Singhal 2011). The empirical evidence thus runs counter to this alternative explanation.
} 
incomes over a seven-year period and consistent consumption data for the first four of those years, for a sample of households in six villages in the states of Andhra Pradesh and Maharashtra. The panel data enables us to compute the theoretically-relevant intertemporal mean values for consumption and income for each household. ${ }^{26}$

We divide up the households in each caste into quintiles of the within-caste income distribution to compute mean consumption and mean income in each income class. Restricting the sample to castes with at least 20 members represented in the data, we have seven castes among 552 households in the six villages. Table 5, Column 1, reports relative income, measured by the ratio of average income in the income class to average income in the highest income class, averaged across all castes. Relative income is increasing across income classes by construction. Column 2 reports the corresponding statistics for relative consumption. A comparison of Column 1 and Column 2 indicates that there is substantial redistribution within castes. The consumption ratio exceeds the income ratio for each income class, with the consumption-income ratio in Column 3, or more correctly the ratio of ratios, close to four for the lowest income class.

With just 500 households and 7 castes, the ICRISAT sample is too small to test the second prediction of the model, which is that relatively wealthy households within their caste should be more likely to have migrant members. The 2006 Rural Economic Development Survey (REDS), collected information from over 119,000 households residing in 242 villages in 17 major Indian states on the migrant status of each household; i.e. whether any adult male (father, brother, or son of the head) had permanently left the village in the preceding five years, the income of each household in the prior year, and its sub-caste affiliation. ${ }^{27}$ In the data, permanent migrants are defined as those who are no longer members of the local household. ${ }^{28}$ Non-resident household members who are temporary migrants are included in the household roster, as is standard in most household surveys.

To test how relative wealth affects migration, we construct a measure of the household's

\footnotetext{
${ }^{26}$ These data provide the value of all foods and non-foods consumed, including self-produced and purchased items measured at various times over the year, that can be summed to obtain an annual total. The Indian CPI for agricultural laborers is used to compute real consumption values expressed in 2005 rupees. Average real (inflation-adjusted) annual income is also computed for the same households over the entire seven-year period, including wages, salaries, and farm and non-farm income, but excluding any transfers and remittances.

${ }^{27}$ The selection of villages was meant to provide a representative sample of rural Indian households. Any sample of villages will not yield a representative sample of castes, unless castes are distributed evenly across villages. For the castes represented in the data, however, the income distribution derived from the randomly sampled villages will be representative of the caste-level income distribution.

${ }^{28} \mathrm{We}$ cannot determine whether any of the departed household members were formerly the household head. There are few instances of entire households migrating in India - data from the 1999 and 2006 REDS indicates that less than 10 percent of rural households that were present in the 1999 round could not be located in the same village in 2006. The comparable statistic for Indonesian households from the first two waves of the IFLS is 18 percent over just four years (Thomas et al. 2001). The Indonesian data also disentangle migration, which accounts for two-thirds of the missing households, from attrition. Assuming that two-thirds of missing Indian households also migrated, this implies that the annual rate of permanent household migration is less than one percent.
} 
average income over time. A shortcoming of the REDS data is that it provides incomes only in the year preceding the survey and includes transfers. To address this limitation, we impute average income for each household using the ICRISAT panel data set and a vector of household and village-level variables that are common to both the REDS and ICRISAT data sets. We first estimate, using ICRISAT data, the relationship between average annual household income over all seven years excluding all transfers and the vector of (common) household and village characteristics, including all the household characteristics interacted with mean rainfall. The vector of regressors have sufficient predictive power, with an $\mathrm{R}$ squared around 0.3. The coefficients obtained from the regression estimated with ICRISAT data are then used to impute average income for each of the REDS households, based on their characteristics. ${ }^{29}$

As noted, the ICRISAT villages are located in Andhra Pradesh and Maharashtra. For comparability, we restricted the REDS sample to four geographically contiguous and broadly similar South Indian states - Maharashtra, Andhra Pradesh, Tamil Nadu, and Karnataka - when imputing incomes. ${ }^{30}$ Average consumption is also imputed for the REDS households from ICRISAT consumption data using the same method and the same firststage specification that was used to impute average income. Table 5, Columns 4-6 replicate the computations carried out with the ICRISAT data for the REDS sample. A comparison of Column 4 and Column 5 indicates that, as is true for the ICRISAT households (where no values are imputed), there is substantial redistribution within castes. The consumption ratio exceeds the income ratio for each income class, with the consumption-income ratio in Column 6 , or more correctly the ratio of ratios, close to three for the lowest income class.

Finally, Column 7 reports migration rates by income class. Consistent with the theory and the redistribution documented in Table 5, we see that migration rates are increasing in relative income. A household's relative position within its caste's income distribution will be positively correlated with its absolute income. The statistics reported in Column 7 do not account for the direct effect of (absolute) household income on migration, which would dampen the increase in migration across relative income classes if wealthier households are less likely to migrate for other reasons. The regression analysis that follows will control for the direct effect of the household's income on migration.

\footnotetext{
${ }^{29}$ Both data sets provide household-level information on total land area (together with a binary variable indicating whether the household is landless), irrigated area, soil type (red, black, sandy) and soil depth, household size, the number of earners, and the occupation of the household head. Each data set also provides, at the village level, a time-series of rainfall; daily rainfall for all seven years for the ICRISAT survey and monthly data over an eight-year period starting in 1999 for the REDS, from which we construct village-level mean annual rainfall and the variance of annual rainfall. When imputing average income for REDS households with permanent male migrants, we included those migrants among the earners. The most important determinants of household income are landholding size and number of male earners.

${ }^{30}$ The advantage of including Karnataka and Tamil Nadu is that they increase the number of observations, particularly in the structural estimation where households are aggregated by income class in each caste. The reduced-form results reported below are largely unchanged and statistically significant when the sample is restricted to the non-ICRISAT states (Karnataka and Tamil Nadu).
} 


\subsection{Reduced-Form Estimates}

Proposition 1 indicates that relatively wealthy households in their caste should be more likely to have migrant members. We thus estimate a regression of the form

$$
M_{i}=\pi_{0}+\pi_{1} y_{i}+\pi_{2} \bar{y}_{i}+\epsilon_{i},
$$

where $M_{i}$ indicates whether any male member of household $i$ had moved permanently from the village, $y_{i}$ is the household's average income over time, and $\bar{y}$ is the corresponding average statistic for its caste. As discussed above, this information is available from the 2006 REDS census.

Under the assumption that the (proportional) income-gain from migration, $\tilde{\epsilon}$, is independent of rural income, $M_{A}$, the theory predicts that (i) $\pi_{1}>0$ and (ii) $\pi_{2}<0$. However, household income could directly determine migration due to liquidity constraints or riskaversion. Higher income households also have larger numbers of males and this may increase the probability that any male will migrate. The $\pi_{1}$ coefficient can thus no longer be easily interpreted. The key prediction of the theory is $\pi_{2}<0$; conditional on the household's own income, an increase in caste income implies it is relatively less wealthy and, therefore, should be less likely to have migrant members.

Table 6, Column 1 reports the estimates of equation (9). All coefficient standard errors are bootstrapped to account for the use of imputed incomes. As predicted by the theory, the estimated coefficient on caste income, $\hat{\pi}_{2}$, is negative and significant. This result provides support for the theory in which the migration decision is made in the context of a caste network, and networks redistribute income in favor of the poor. The positive and significant coefficient on own household income, $\hat{\pi}_{1}$ in Column 1 , is also consistent with the theory but, as noted, there are other interpretations. ${ }^{31}$

Proposition 2 indicates that households who face greater rural income-risk should be less likely to have migrant members. We test this prediction by including the normalized rural income-risk faced by the household as an additional regressor in Table 6, Column 2. Income risk in our theory is measured by the coefficient of variation of the household's income, squared. We construct the variance of the household's income over time using the same method that was used to impute average income. ${ }^{32}$ Using the constructed variance to compute income-risk, we see in Table 6, Column 2 that households facing higher rural

\footnotetext{
${ }^{31}$ Our analysis with 2006 REDS data restricts the sample to castes with at least 30 households in the census. This ensures that there will be a sufficient number of households in each income class in the structural estimation, where castes are divided into 4-6 income classes. The reduced-form results in Table 6 are robust to restricting the sample to castes with at least 10 households in the 2006 REDS census.

${ }^{32}$ The specification in the first step, using ICRISAT data, is the same, except that the household characteristics are interacted with the variance of village rainfall in the ICRISAT villages. The set of household and village level regressors once again have sufficient power, with an R-squared around 0.3. The estimated coefficients from the first step are subsequently used to predict the variance of income for each of the REDS households using their characteristics and village-level rainfall variances. We estimate the relationship between log-variance and the household and village characteristics in the first step. Predicted log-variance for
} 
income-risk are indeed less likely to have migrant members. While this result is consistent with our theory in which migration results in the loss of risk-reducing network services, it is inconsistent with standard models of individual migration in which adverse origin characteristics lead to higher out-migration rates. Recall that the relationship between relative wealth and migration in Proposition 1 was derived conditional on rural income-risk. The relationship between income-risk and migration in Proposition 2 was derived conditional on household income (and the household's position in the caste income distribution). The specification in Column 2 allows us to (simultaneously) estimate these conditional relationships, as required by the theory.

The theory does not specify what constitutes the domain of the network. Although we assume that rural insurance networks are organized around the caste, they could potentially be organized at the level of the village, as assumed in previous studies on risk-sharing in India; e.g. Townsend 1994, Ligon 1998. To address this possibility, we include mean village income as an additional regressor in Table 6, Column 3. Consistent with Mazzocco and Saini (2012) who report full risk-sharing at the caste level, but reject full risk-sharing in the village with ICRISAT data, we see that the coefficient on mean caste-income is stable and remains highly significant, whereas the corresponding coefficient on village income is small and imprecisely estimated. One remaining possibility is that the estimated village-income coefficient is biased because village income is correlated with village infrastructure, which directly determines migration. To address this possibility, we include variables indicating whether a bank, secondary school, or health center is located in the village in Table 6, Column 4. Although the infrastructure variables are jointly highly significant, the remaining coefficient values are largely unchanged.

We believe that the caste is exceptionally effective at consumption-smoothing because of its large size and scope (extending over many villages). While the preceding results indicate that insurance networks in India are organized around the caste rather than the village, they do not tell us whether the network extends beyond village boundaries. To answer this question, we replace village income with the mean income of caste households within the village in Table 6, Column 5. Reassuringly, the complete caste-income coefficient maintains its size and significance, while the restrictive caste-income measure has little effect on migration and is statistically insignificant. The stability of the caste-income coefficient to the inclusion of a vector of village-level variables indicates that the results are not being driven by unobserved village-level effects. Nevertheless, as a final robustness test, we include a full set of village fixed effects in Column 6. Although the caste-income coefficient is now only statistically significant at the 12 percent level (one-tailed test), it remains as large (in absolute magnitude) as it was with the benchmark specification in Column 2. Results

the REDS households can then be transformed to the variance of income, ensuring that no negative values are obtained. 
from a Hausman test (available from the authors) indicate that the difference in the caste income coefficient between the benchmark specification and the specification with village fixed effects is not significant at the 5 percent level. The difference between the household income coefficients is also not statistically significant, at any level. The only statistically significant change is for the income-risk coefficient, but that coefficient is highly significant in both specifications (and gets more negative in the fixed effects specification). Overall, our results provide strong support for the hypothesized trade-off between the insurance provided by rural caste-based network and the income-gain from migration. Those households that benefit less (more) from the rural network are more (less) likely to have migrant members.

\subsection{Structural Estimates}

Having found evidence consistent with the theory, we now estimate the structural parameters of the model. The structural estimates are used to (i) provide independent support for the redistribution within castes that is predicted by the theory, and (ii) to carry out counter-factual simulations that compare the sensitivity of migration to the rural-urban wage gap and formal insurance. We also conduct counter-factual policy simulations that quantify the mobility-enhancing effects of a government safety net for poor households and a credit scheme benefiting wealthy households.

There are two exogenous variables in the model, measured at the level of the incomeclass, $k$ : mean-income, $M_{A k}$, and normalized risk, $R_{A k} \equiv V_{A k} / M_{A k}^{2}$. While there is a single caste (community) in the theoretical analysis, there are 100 castes in the 2006 REDS census, which we use for the structural estimation. To be consistent with the model, we thus proceed to average mean-income, $M_{A i}$, and the variance of income, $V_{A i}$, which were previously imputed for each household $i$, across all household in each income-class, $k$, within each caste, $j$, to obtain $M_{A k j}, R_{A k j}$. The specifications that we report partition the households within each caste into income quintiles, but the results are robust to using four or six income classes.

To understand how the model is estimated, suppose, to begin with, that the $\beta$ parameter and the $F$ function are known. For a given income-sharing rule in caste $j$, described by the $\lambda_{k j}$ vector, we can then solve for participation in each income-class, $N_{k j}$, from the fixed-point conditions, equation (7), after substituting in the expressions for meanconsumption with insurance $M_{I k j}$ and normalized consumption-risk with insurance $R_{I j}$ from equations (5) and (6). The total surplus generated by the insurance arrangement can then be computed in caste $j$ from equation (8). Searching over $\lambda_{k j}$, the income-sharing rule that is ultimately selected in caste $j$ will maximize the total surplus. If the model is correctly specified, predicted migration (which is one minus the participation rate) will match actual migration at that sharing-rule. 
Now suppose that $\beta$ is unknown and must be estimated, but continue to assume that the $F$ function is known. For an arbitrary $\beta$ we can solve for the surplus-maximizing $\lambda_{k j}$, as described above. However, predicted migration will no longer match actual migration. To estimate $\beta$, we exploit the fact that migration in each income-class in each caste will decline as this parameter increases. There thus exists a unique $\beta$ for which overall predicted migration, across all income-classes in all castes, matches actual migration. This will be our best estimate of $\beta$. We match on overall migration to estimate $\beta$ because a unique solution is assured and because this moment will be the outcome of interest in the counter-factual simulation that follows.

The estimation procedure described above was based on the assumption that the $F$ function, which characterizes the distribution of income-gains from migration, $\epsilon$, was known. We now proceed to describe how this function is derived. Recall that we made three assumptions about the $\epsilon$ distribution in the model: (i) the left support is equal to zero, (ii) the right support is unbounded, and (iii) the density of the distribution is declining in epsilon. The exponential distribution satisfies each of these assumptions and so we assume that $\epsilon$ is distributed exponentially. An additional advantage of the exponential distribution is that it is characterized by a single parameter, which we denote by $\nu ; F(\epsilon)=1-e^{-\nu \epsilon}$, where $E(\epsilon)=1 / \nu$.

The distributional parameter, $\nu$, is estimated in two steps. We first use REDS and NSS data to compute the average income-gain from migration for households with permanent male migrant members in the 2006 REDS census. The household's land value, the number of working-age adults, and the education of the household head (which we assume applies to all working members) is available from the REDS census. Urban and rural wages, by education category, are available from the NSS. These data sources can be combined to compute the income-gain from migration, $\tilde{\epsilon}$, and its utility equivalent, $\hat{\epsilon}=\log (1+\tilde{\epsilon}) .{ }^{33}$ We assume that this derived income-gain, $\hat{\epsilon}$, is the representative (median) value for households with migrants. For example, if 4 percent of households have permanent migrant members, then $\hat{\epsilon}$ applies to a household at the $98^{\text {th }}$ percentile of the epsilon distribution. This assumption, together with the properties of the exponential distribution, can be used to derive the distributional parameter:

$$
\nu=\frac{-\log (x / 200)}{\hat{\epsilon}}
$$

where $x$ equals four in the preceding example. Once $\nu$ is computed, the risk-parameter, $\beta$,

\footnotetext{
${ }^{33}$ We compute average rural income as 5 percent of the household's total asset holdings at the beginning of the reference period (one year before the survey round) plus labor income, based on the assumption that the adults in the household work for 312 days in the year. Let $V$ be the household's asset value, $L$ the number of adults, and $W_{U}, W_{R}$ the education-adjusted urban and rural wages from the NSS. The average number of working-age adults per household in the 2006 REDS census is 1.4, and so it is reasonable to assume that a single individual migrates. The income-gain from migration in that case is $\frac{312\left(W_{U}-W_{R}\right)}{0.05 V+312 W_{R} L}$. This statistic is averaged across all households with migrants.
} 
can be estimated as described above.

As a basis for comparison with the estimates that follow, Table 7, Columns 1-2 list relative consumption and migration in each of the five relative income-classes (averaged across all castes). Columns 3-4, report the $\beta$ estimate, predicted relative consumption, $\lambda_{k}$, and predicted migration, $1-N_{k} / P_{k}$, in each of those classes, $k$ (once again averaged across all castes, $j$ ). Jack-knifed standard errors, constructed by removing one caste at a time and re-estimating the model, are reported in parentheses. ${ }^{34}$ The point-estimate for the $\beta$ parameter is 1.4. Similar results are obtained with four and six income-classes in Appendix Table A3. $\beta<1$ if migration reduces income-risk, as commonly assumed (although the theoretical results and the structural estimation do not require this condition to be satisfied). We will see momentarily that $\beta$ does decline, and is much more precisely estimated, with a flexible specification of the model.

The $\beta$ parameter is estimated by matching on overall migration, which is 4.3 percent. Notice, however, that migration rates predicted by the model are lower (higher) than actual migration rates in low (high) income classes. In contrast, relative consumption levels (lambdas) predicted by the model match closely with actual consumption. We cannot reject that predicted and actual relative consumption are statistically equal, at conventional levels, in each income class and across all specifications in Table 7 . The match in terms of magnitudes is very close (less than 5 percent error for each income-class with the benchmark specification with a single $\nu) \cdot{ }^{35}$ This close match in predicted and actual lambdas is especially striking, given that consumption data are not used to estimate the model. The close match also provides support for our use of a utilitarian social welfare function, placing equal weight on all income classes in equation (8). The substantial redistribution documented in Table 5 appears to be driven entirely by an attempt to equate marginal utilities across income classes.

One possible explanation for the mismatch between predicted and actual migration across income classes is that the income-gain from migration varies with rural income, perhaps because members of wealthier households are better educated. Although the theoretical analysis assumes that the (proportional) income-gain is independent of rural income, we relax this assumption when estimating the model in Table 7, Columns 5-6. The house-

\footnotetext{
${ }^{34}$ The jack-knifed standard error for any parameter $\theta$ is given by the expression $\left[n / n-1 \sum_{i}\left(\theta_{i}-\bar{\theta}\right)^{2}\right]^{1 / 2}$, where $n$ is the number of times the model is re-estimated, $\theta_{i}$ is the parameter estimate when it is re-estimated for the $i^{\text {th }}$ time, and $\bar{\theta}$ is the average across all $\theta_{i}$. In our case, with 100 castes, $n=100$.

${ }^{35} \mathrm{An}$ alternative approach to compare the closeness of the match, suggested by a referee, would be to compute the probability that the predicted and actual lambdas are as close as they are by random chance. We implement this test for the lowest relative income-class, since it will certainly not subsidize any other income-class and so the range of feasible lambdas is known. Given that the relative income for the lowest income-class is 0.31 from Table 5 , lambda must lie in $[0.31,1]$. If the predicted lambda is distributed uniformly over this range, the probability that it will lie within 0.04 of the actual lambda, as observed for the benchmark specification in Table 7, is 12 percent. The standard error for the lowest income class is also small enough for us to reject that there is no redistribution (lambda is equal to 0.31) with greater than 95 percent confidence.
} 
holds in the 2006 REDS census are divided into five absolute income classes, without regard to their caste affiliation, and the $\nu$ parameter is then computed in each income class using the procedure described above. ${ }^{36}$ Each relative income-class $k$ in caste $j$ can be mapped into an absolute income-class based on its mean income, $M_{A k j}$. The $\nu$ parameter computed for that absolute income-class is then assigned to class $k$ in caste $j$. The results with this flexible specification in Columns 5-6 are very similar to the results obtained with the benchmark specification in Columns 3-4. Allowing the income-gain from migration to vary with rural income evidently does not reduce the mismatch between predicted and actual migration.

Although the theory focuses on the constraints faced by individuals migrating independently, the empirical analysis must take account of the small number of castes that have established urban networks in the city. While most castes report low migration rates in our data, a few do have substantial rates of permanent male migration. We account for these caste-level differences by estimating a flexible specification that allows for a caste-specific $\nu$ parameter. The income-gain computed for households with migrants $\hat{\epsilon}$, using REDS and NSS data as described above, does not vary substantially across castes. The important difference is the point in the epsilon distribution where these households are located. For a caste with a strong network and many migrants, $x$ in equation (10) is relatively large, which implies that $\nu=1 / E(\epsilon)$ will be small. A strong urban caste network, reflected in a high level of permanent migration in the data, thus effectively increases the income-gain from migration. Despite the flexibility that is introduced with $100 \nu$ parameters, the pattern of lambdas and migration in Columns 7-8 is very similar to the benchmark estimates obtained with a single $\nu$ parameter. Notice that the $\beta$ coefficient is now smaller than one, consistent with the standard presumption that migration reduces income-risk, although it continues to be imprecisely estimated.

We assumed, when deriving the theoretical results, that there was a single $\nu$ and a single $\beta$. The specifications reported in Columns 5-8 relax the first assumption. We now relax the second assumption by allowing beta to vary with rural household income (there is no reason to allow beta to vary by caste if households with migrants are excluded from their rural insurance networks). Recall that beta reflects the income diversification that accompanies migration as well as access to non-network consumption-smoothing mechanisms. There is no obvious reason why the reduction in income-risk through migration should vary with rural income. Moreover, while we would expect wealthier households to have greater access

\footnotetext{
${ }^{36}$ Appendix Table A4 shows, with five absolute income-classes, that land value, the number of workingage adults, and the education of the household head are all generally increasing across income classes as expected. Although the NSS data indicate that the rural-urban wage gap is increasing with education (Hnatkovskay and Lahiri 2013), wealthier households are starting from a higher rural income-base and so the proportional gain in income will naturally be smaller for them. There is no obvious relationship between absolute income and the income-gain from migration, which is reflected in the migration rate, in Table A4.
} 
to private credit, the relationship between wealth and beta is theoretically ambiguous. Consider, for example, two households trying to smooth their consumption with credit, where one household has twice as much income as the other in each state of the world. To smooth consumption completely, the wealthier household must receive twice as much credit in each state of the world. If land, the chief source of wealth in rural India, is not fully collateralizable, then this condition may or may not be satisfied and the beta-wealth relationship will be ambiguous.

To empirically assess the relationship between rural wealth and beta, we augmented the regression specification reported in Table 6 , Column 2 by interacting normalized incomerisk with household income. Although not reported, the coefficient on the interaction term is negative, while the uninteracted risk coefficient remains negative. This implies that wealthier households respond more to rural income-risk and, hence, that beta is larger for them. The structural estimates in Table 7, Columns 9-10 allow for this possibility by setting beta to be a linear function of average income in each relative income-class within each caste; $\beta=\alpha+\gamma M_{A k j}$.

Predicted migration rates were too high (low) for higher (lower) relative income-classes with a single beta parameter. With the flexible specification, we thus expect the gamma coefficient to be positive to bring predicted migration in line with actual migration. This would also be consistent with the reduced-form results discussed above. The estimated coefficients in Columns 9-10 are consistent with this prediction. Since there are two parameters to estimate $-\alpha$ and $\gamma$ - we match on two moments: overall migration in the lowest and the highest relative income class. ${ }^{37}$ It is reassuring to observe that predicted and actual migration now match closely in the remaining three income-classes. We are even able to generate the non-monotonicity from relative income-classes three to five, despite the fact that $\beta$ is specified to be increasing linearly in mean-income $M_{A k j}$, without regard to the relative position of group $k$ in caste $j$.

To compare the parameter estimates with the flexible specification with what we obtained earlier in Columns 3-8, we use the estimated $\alpha$ and $\gamma$ parameters to compute $\beta$ for the representative household with mean-wealth in the REDS census. Jack-knifed standard errors for the $\beta$ parameter are constructed using the procedure described above. The $\beta$ parameter with the flexible specification is similar in magnitude to what we obtained earlier, lying close to one, although it is much more precisely estimated. The $\beta$ estimates in Table 7 do not allow us to conclusively establish whether or not $\beta$ is less than one. However, if we take a different approach that exploits variation in household income in the sample, then 86 percent of the households in the REDS census would have a $\beta$ coefficient less than one (based on the estimated $\alpha$ and $\gamma$ coefficients). This result, coupled with the fact that

\footnotetext{
${ }^{37}$ The standard errors for these two income classes in Column 10 simply reflect the sampling error that is generated when we re-estimate the model, removing one caste at a time, in the jack-knife procedure.
} 
households facing greater rural income-risk were nevertheless less likely to have migrant members in Table 6, indicates that the loss in network insurance must be large enough to dominate the substantial income-gain and the (possible) risk-reduction associated with migration.

Given that the structural model appears to fit the data reasonably well, we use the estimated parameter values to perform counter-factual simulations that quantify the magnitude of the mobility restrictions we have uncovered. There are two structural parameters in the model: the risk parameter, $\beta$, and the income-gain parameter, $\nu$. We reduce the $\beta$ parameter to assess the effect of an improvement in formal insurance on migration, taking as given the rural insurance arrangements that are in place. We assess the sensitivity of migration to changes in the income-gain from migration by increasing the $\nu$ parameter.

Figure 7 reports overall migration rates over a range of counter-factual $\beta$ values, using both the benchmark specification (single $\nu$, single $\beta$ ) and the flexible specification (castespecific $\nu, \beta$ increasing in household income). A 50 percent decline in $\beta$, which is still quite far from full insurance ( $\beta$ equal to zero) more than doubles the migration rate from 4 to 9 percent with the more precisely estimated flexible specification, highlighting the importance of risk in restricting mobility. How responsive is migration to an exogenous change in the income-gain from migration? Given historically low migration rates, despite the persistently large wage gap in India, we would expect predicted migration to be insensitive to changes in the income-gain if the model is correct. Counter-factual simulations in Figure 7 that vary the value of the $\nu$ parameter, but retain the assumption that formal insurance is unavailable, verify that this is indeed the case. An 80 percent increase in the $\nu$ parameter, which corresponds to an average decline in the income-gain from 18 percent to 10 percent lowers migration by just one percentage point. This result further emphasizes the central message of this paper, which is that inadequate access to formal insurance, rather than wage differentials as commonly assumed in models of migration, may explain much of the low mobility in India.

\subsection{Testing the Mechanism}

The key assumption underlying our theory is that permanent male migration is associated with a loss in network services. We test this assumption by examining how a household's relative wealth affects three variables: out-migration, network participation, and out-marriage. Recall that marriage within the caste is a prerequisite for participation in the network.

Each REDS round consists of a census of households in the representative sample of villages, followed by a detailed survey of a sample of households in those villages. The survey collects information on permanent migration by adult males, as in the census. In 
addition, it collects information on financial transactions within the caste, which directly measures participation in the insurance network, as well as on marriage within the caste by household members. ${ }^{38}$

Although the number of households in the detailed survey is relatively small, a major advantage over the census is that they can be linked over successive REDS rounds. We thus construct a panel, using the surveyed households in the 1982 and 1999 rounds of the REDS, for the joint test of the key theoretical assumption. ${ }^{39}$ We eliminate all castes with less than 10 households in the REDS survey, and then proceed to estimate the following equation:

$$
X_{i t}=\pi_{1} y_{i t}+\pi_{2} \bar{y}_{i t}+f_{i}+\epsilon_{i t},
$$

where $y_{i t}$ is household $i$ 's average income in survey round $t(1982,1999), \bar{y}_{i t}$ is the corresponding caste average, and $f_{i}$ is a household fixed effect. This is the same specification as equation (9), except that household fixed effects and time subscripts are included. Equation (11) is separately estimated with out-migration, out-marriage, and network participation as dependent variables.

Average household income, $y_{i t}$, could be determined by unobserved household attributes that independently determine the outcomes of interest. These attributes could also be correlated with caste income, $\bar{y}_{i t}$ to the extent that they are correlated across households within the caste. Differencing over the two years allows us to purge these fixed attributes,

$$
\Delta X_{i t}=\pi_{1} \Delta y_{i t}+\pi_{2} \Delta \bar{y}_{i t}+\Delta \epsilon_{i t}
$$

However, shocks to income could still be correlated with unobserved changes in the determinants of out-migration, out-marriage, and network participation $\Delta \epsilon_{i t}$; for example, if schools, banks, or other infrastructure that independently changed incomes and the outcomes of interest were introduced in the household's village between 1982 and 1999. To address this concern, we construct instruments for $\Delta y_{i t}, \Delta \bar{y}_{i t}$ in equation (12) above.

We make use of two technological features of the Indian Green Revolution to construct these instruments: (i) only certain parts of the country had access to the new HYV seeds at the onset of the Green Revolution in the late 1960s, and (ii) the returns to investing in the

\footnotetext{
${ }^{38}$ Participation in the caste network is measured by a binary variable that takes the value one if the household sent or received caste-transfers (gifts or loans from or to members of the same sub-caste) in the year preceding each survey round. The measures of out-marriage and out-migration are constructed from the 1999 retrospective histories on the marriages and migration of all of the siblings and children of each household head in the sample. From these histories we created a variable indicating whether any child of the household head married outside the caste in the 10-year period prior to each survey date. The measure of out-migration is whether any male aged 20-30 at the time of each survey and residing in the household prior to the survey had left the village permanently by the survey date.

${ }^{39}$ To construct the panel, we start with the sample of households in the 1982 round. Because of household partitioning, many 1982 household members were distributed across multiple households in 1999. We thus aggregate all 1999 households to be consistent with 1982 household boundaries, resulting in a balanced panel over the two years.
} 
HYV technology are much greater on irrigated land. The instrumental variable strategy allows for the possibility that initial availability of HYV technology and access to irrigation were correlated with unobserved village and household characteristics that had long-term effects on the outcomes of interest by including them in the second stage. Exploiting the technological complementarity between HYV and irrigation, only the interaction of these variables, measured in 1971, is used as an instrument for changes in income from 1982 to $1999 .{ }^{40}$ To add statistical power, we include two more instruments: the amount of land inherited by the household head, as reported in the 1982 REDS round, and the triple interaction of inherited wealth, HYV, and irrigation. The corresponding caste-level instruments are the caste averages of the three household-level instruments.

The income variable that we construct depends on the household's assets and the number of working age adults (including permanent migrants, if any). The same procedure was used in the structural estimation to construct the income-gain from migration for households with migrants, except that we now use the village-level daily wage in the survey year rather than the NSS wage to measure labor income. Caste-level income is once again simply the caste average of household incomes. Note that we no longer need to restrict the sample to southern states.

Table 8 reports the instrumental-variable estimates of equation (12). The estimates support the joint hypothesis that conditional on the household's own income an increase in caste income reduces the probability of out-migration and out-marriage, and simultaneously increases the probability of participating in the insurance network. ${ }^{41}$ The point estimates with out-migration as the dependent variable are larger in magnitude than what we obtained in Table 6, possibly because the instruments purge measurement error in the income variables. However, the pattern of coefficients remains the same. These results are difficult to reconcile with alternative explanations that do not make a connection between risk, caste networks, and migration.

\footnotetext{
${ }^{40}$ This instrument is constructed by interacting a binary variable indicating whether anyone in household $i$ 's village used HYV in 1971 with the share of irrigated land in the village in that year. These variables are obtained from the 1971 REDS round, which is at the onset of the Green Revolution but still close enough in time to predict changes in income over the 1982-1999 period.

${ }^{41}$ Standard errors in the FE-IV regressions are clustered at the state rather than the caste level because our instruments are correlated with agricultural extension and irrigation programs at the district level, and because the caste will often span a wide area covering multiple districts within but not across states. Although the Hansen J-statistics indicate that the instruments pass the over-identification test, the Kleibergen-Paap F statistics suggest that weak instruments may be a concern (based on the Stock-Yogo critical values), especially with participation in the network as the dependent variable. Participation in the network is measured over a single year prior to each survey round, which will severely under-estimate the household's actual involvement, especially since the demand for major contingencies occurs very infrequently. Marriage within the caste is thus a more robust measure of network participation and we also have more statistical confidence in these estimates. Appendix Table A5 reports the first-stage parameter estimates. Although the Kleibergen-Paap multivariate weak-instrument test indicates that the results need to be treated with caution, as noted above, the first-stage regressions, separately estimated with household income and caste income as dependent variables, have sufficient power, with large F-statistics and corresponding p-values on the test of joint significance of the excluded variables well below 0.01 .
} 


\section{Conclusion}

This paper provides an explanation for large spatial wage disparities and low male migration in India based on a combination of well-functioning rural insurance networks and the absence of formal insurance. When men migrate permanently to work, they (and their rural households) cannot credibly commit to honoring their future obligations at the same level as households without migrants. They also have an incentive to misreport their urban income. If the loss in network insurance due to these commitment and information problems is sufficiently severe, and alternative insurance is unavailable, then higher paying job opportunities will go unexploited. Imperfections in the insurance market thus give rise to a misallocation in the labor market.

We test this hypothesis by developing and estimating a model of ex ante mutual insurance in which participation and the income-sharing rule are jointly determined. The main theoretical results are (i) that income is redistributed in favor of relatively poor households within the caste, which implies that relatively rich households (who benefit less from the insurance network) should be more likely to have migrant members, and (ii) that households facing greater rural income-risk (who benefit more from the network) should be less likely to have migrant members. We find, using a variety of data sources and estimation techniques, evidence that is consistent with these predictions. Structural estimates of the model allow us to quantify the magnitude of the misallocation due to the absence of formal insurance; a 50 percent improvement in risk-sharing for households with migrant members would increase the migration rate from 4 to 9 percent.

Why does India have migration rates that are so much lower than other comparable developing economies? In our framework, this could be because formal insurance, which includes private credit and government safety nets, is particularly weak in India or because informal insurance works particularly well there. There is no evidence suggesting that credit markets work better in other low-income countries or that superior public safety nets are available. Moreover, research on informal insurance has documented extremely high levels of risk-sharing throughout the developing world, not just in India. There is, however, more to consumption-smoothing than risk-sharing. If the size and geographic scope of the network is small, as it often appears to be; e.g. Udry (1994), Fafchamps and Lund (2003), Angelucci, De Giorgi, and Rasul (2014), then consumption will not be smoothed appreciably even with full risk-sharing. ${ }^{42}$ What is exceptional about India is

\footnotetext{
${ }^{42}$ To see why this is the case, consider a two-person network and a world with two income states: $H$ and $L$, that occur with equal probability and our distributed independently across individuals and over time. With full risk-sharing, each individual consumes $H$ with probability $1 / 4, L$ with probability $1 / 4$, and $(H+L) / 2$ with probability $1 / 2$, so there is still substantial variation in consumption. This variation will decline, however, as the number of individuals in the network increases. It will also decline if incomes are negatively correlated; i.e. if income-risk can be diversified, which will be the case if the network is more dispersed.
} 
the size and spatial-scope of the caste network, which appears to have given rise to an equilibrium with strong rural insurance networks, weak formal insurance, and low mobility.

The model was developed to explain low mobility in India, but it is also useful in assessing the mobility and distributional impacts of interventions that provide formal insurance to rural households. One strategy would be to increase access to private credit, perhaps by allowing rural households to collateralize their assets. In our model, this would result in a decline in $\beta$ for wealthier households. Figure 7 reports the results of a policy experiment in which we proportionately reduce $\beta$ in the top three absolute income classes, using the flexible specification in Table 7 , Columns $9-10 .{ }^{43}$ As can be seen, migration increases substantially for the highest relative income class as $\beta$ declines. Although not reported, there is a substantial increase in migration for the next two income classes as well. This exit from the network would adversely affect the ability of the households that remain to smooth their consumption. More interestingly, this results in an accompanying decline in redistribution within the caste, as a way of getting the wealthier households to stay. For the lowest income class, for example, $\lambda$ declines from 0.75 to 0.48 , which is not far from the sharing-rule without redistribution $(\lambda=0.31)$. Thus, while a credit program may reduce the labor-market misallocation, it will have large and unintended negative distributional consequences for the lower income classes who continue to have low migration rates. An evaluation of this credit program that failed to account for the interaction of the treatment with underlying informal institutions would be hard-pressed to explain why consumption declined in the untreated group.

We can also use the structural estimates to assess an alternative policy intervention that reduces $\beta$ for lower absolute income classes. The policy in this case could be a government employment guarantee scheme for the rural poor, such as India's NREGA. If rural insurance networks were ignored, one would expect such a scheme to improve the welfare of the poor and reduce their migration from rural areas. What we observe instead in Figure 8, consistent with our theory, is that migration is increasing for the lowest (treated) income classes as $\beta$ declines. Migration increases as much for the highest income class (which does not benefit directly from the scheme) as the lowest income class. The migration rate increases in the highest income class because the increased exit by the directly targeted low income households reduces the ability of the network to smooth consumption. Once again, spillovers within the network have substantial impacts on household behavior.

\footnotetext{
${ }^{43}$ Access to credit depends on absolute (not relative) wealth. Each relative income class, $k$, within each caste, $j$, is thus assigned to one of five absolute income classes on the basis of its mean income, $M_{A k j}$. Recall that the absolute income classes were constructed by sorting households in the REDS census by average income, without regard to caste affiliation. We lower $\beta \equiv \alpha+\gamma M_{A k j}$ for those relative income classes, $k j$, that are in the top three absolute income classes in Figure 7. The counter-factual simulation that follows in Figure 8 reduces $\beta$ for relative income classes, $k j$, in the bottom two absolute income classes.
} 


\section{Appendix}

Proof of Lemma $1 \Delta M=0$ from equation (2). $\Delta R>0$ by assumption. The term in parentheses in equation (4) is greater than zero. This implies, from assumption A1, that $F(\Delta M+\Delta R)$ is greater than zero. $F(\Delta M+\Delta R)>N / P$ at $N=0$. Moreover, $F(\Delta M+\Delta R)$ is less than one from assumption A2. $F(\Delta M+\Delta R)<N / P$ at $N=P$. $F(\Delta M+\Delta R)$ is increasing in $N$ because $R_{I}$ is decreasing in $N$ (hence, $\Delta R$ must be increasing in $N)$. By a continuity argument, a fixed point, $N^{*} \in(0, P)$ at which equation (4) is satisfied must exist.

From assumption $\mathrm{A} 3$, and given that $d R_{I} / d N<0, d^{2} R_{I} / d N^{2}>0$ from equations (2) and (3), $F(\Delta M+\Delta R(N))$ is strictly concave:

$$
\begin{gathered}
F^{\prime}(\Delta M+\Delta R)=-f \cdot \frac{1}{2} \frac{d R_{I}}{d N}>0 \\
F^{\prime \prime}(\Delta M+\Delta R)=f^{\prime} \cdot\left[\frac{1}{2} \frac{d R_{I}}{d N}\right]^{2}-f \cdot \frac{1}{2} \frac{d^{2} R_{I}}{d N^{2}}<0 .
\end{gathered}
$$

This implies that the fixed point, which satisfies equation (4), is unique to complete the proof of Lemma 1.

Proof of Proposition 1 We first establish that a unique fixed point exists for the sharing rule without redistribution.

Lemma 2. Equilibrium participation in each income class $k \in\{L, H\}$ is characterized by a unique fixed point, $N_{k}^{*} \in\left(0, P_{k}\right)$.

Without redistribution, $\Delta M_{k}=0$ from equation (5). As with the case without income heterogeneity, we assume that $\Delta R_{k}>0$. The term in parentheses in equation (7) is positive for both income classes. The right hand side of the equation is strictly positive from assumption A1 and less than one from assumption A2. Following the same argument as in Lemma 1, this implies that the $F$ function must cross the $N_{k} / P_{k}$ line in equation (7) at least once.

For a unique fixed point to be obtained, we need in addition that the $F$ function should be strictly concave. The conditions for strict concavity corresponding to inequalities (13) and (14) are

$$
\begin{gathered}
F^{\prime}\left(\Delta M_{k}+\Delta R_{k}\right)=f \cdot\left(\frac{1}{M_{I k}} \frac{d M_{I k}}{d N_{k}}-\frac{1}{2} \frac{d R_{I}}{d N_{k}}\right)>0 \\
F^{\prime \prime}\left(\Delta M_{k}+\Delta R_{k}\right)=f^{\prime} \cdot\left(\frac{1}{M_{I k}} \frac{d M_{I k}}{d N_{k}}-\frac{1}{2} \frac{d R_{I}}{d N_{k}}\right)^{2}+f \cdot\left(\frac{d}{d N_{k}}\left[\frac{1}{M_{I k}} \frac{d M_{I k}}{d N_{k}}\right]-\frac{1}{2} \frac{d^{2} R_{I}}{d N_{k}^{2}}\right)<0 .
\end{gathered}
$$

Without redistribution, $\lambda_{k}=M_{A k} / M_{A K}$. It follows from equation (5) that $M_{I k}=M_{A k}$ and, hence, that $d M_{I k} / d N_{k}=0$. Given assumption A3, the preceding inequalities will evidently be satisfied if $d R_{I} / d N_{k}<0$ and $d^{2} R_{I} / d N_{k}^{2}>0$.

From equation (6), 


$$
\frac{d R_{I}}{d N_{k}}=\frac{V_{A k} \sum_{k} N_{k} M_{A k}-2 M_{A k} \sum_{k} N_{k} V_{A k}}{\left(\sum_{k} N_{k} M_{A k}\right)^{3}} .
$$

Given that $R_{A k}$ is the same (denoted by $R$ ) in all income classes, and that $N_{k}$ is the same (denoted by $N$ ) in all income classes in the absence of redistribution since they are of equal size,

$$
\frac{d R_{I}}{d N_{k}}=\frac{R\left[M_{A k}^{2} \sum_{k} M_{A k}-2 M_{A k} \sum_{k} M_{A k}^{2}\right]}{N^{2}\left(\sum_{k} M_{A k}\right)^{3}} .
$$

Collecting terms, the required condition is

$$
M_{A k}<2 \frac{\sum_{k} M_{A k}^{2}}{\sum_{k} M_{A k}}
$$

From equation (15),

$$
\frac{d^{2} R_{I}}{d N_{k}^{2}}=\frac{-4 V_{A k} M_{A k} \sum_{k} N_{k} M_{A k}+6 M_{A k}^{2} \sum_{k} N_{k} V_{A k}}{\left(\sum_{k} N_{k} M_{A k}\right)^{4}} .
$$

Simplifying as above,

$$
\frac{d^{2} R_{I}}{d N_{k}^{2}}=\frac{R\left[-4 M_{A k}^{3} \sum_{k} M_{A k}+6 M_{A k}^{2} \sum_{k} M_{A k}^{2}\right]}{N^{3}\left(\sum_{k} M_{A k}\right)^{4}} .
$$

Collecting terms, the required condition is

$$
M_{A k}<\frac{3}{2} \frac{\sum_{k} M_{A k}^{2}}{\sum_{k} M_{A k}}
$$

The condition in equation (18) is binding. For the case with two income classes, assume without loss of generality that $M_{A L}=M(1-\theta), M_{A H}=M(1+\theta)$. We showed in Lemma 1 that there is a unique fixed point when $\theta=0$. We now show that the condition in equation (18) is satisfied for all $\theta \geq 0$. With two income classes, that condition can be rewritten as

$$
M_{A H}<\frac{3}{2} \frac{\left(M_{A L}^{2}+M_{A H}^{2}\right)}{\left(M_{A L}+M_{A H}\right)},
$$

which reduces to

$$
3 \theta^{2}-2 \theta+1>0
$$

The left hand side of the preceding inequality is positive for $\theta \geq 0$ (reaching a minimum value of $2 / 3$ at $\theta=1 / 3$ ) to complete the proof of Lemma 2 .

The next step in proving Proposition 1 is to show that an increase in $\lambda$, evaluated at $\lambda=M_{A L} / M_{A H}$, must increase the surplus generated by the insurance network.

$$
W=\sum_{k=L, H} N_{k} \epsilon_{I k}-P_{k} \int_{0}^{\epsilon_{I k}} \epsilon f(\epsilon) d \epsilon
$$

where $\epsilon_{I k}=\Delta M_{k}+\Delta R_{k}$. 
Differentiate $W$ with respect to $\lambda$, applying Leibniz integral rule and noting that $\Delta M_{k}$, $R_{I}$ are functions of $N_{L}$ and $N_{H}$,

$$
\frac{d W}{d \lambda}=\sum_{k=L, H}\left[N_{k}-P_{k} \epsilon_{I k} f\left(\epsilon_{I k}\right)\right] \frac{d \epsilon_{I k}}{d \lambda}+\left\{\epsilon_{I k}+\sum_{m=L, H}\left[N_{m}-P_{m} \epsilon_{I m} f\left(\epsilon_{I m}\right)\right] \frac{d \epsilon_{I m}}{d N_{k}}\right\} \frac{d N_{k}}{d \lambda}
$$

$N_{k}=P_{k} F\left(\epsilon_{I k}\right)$ and so the terms in square brackets must be positive. Moreover, at $\lambda=$ $M_{A L} / M_{A H}, \epsilon_{I L}=\epsilon_{I H}$ and $N_{L}-P_{L} \epsilon_{I L} f\left(\epsilon_{I L}\right)=N_{H}-P_{H} \epsilon_{I H} f\left(\epsilon_{I H}\right)$. Thus, the sign of $d W / d \lambda$ depends on $d \epsilon_{I k} / d \lambda, d \epsilon_{I m} / d N_{k}, d N_{k} / d \lambda$. We show below that $d \epsilon_{I L} / d \lambda>\mid$ $d \epsilon_{I H} / d \lambda\left|, d \epsilon_{I m} / d N_{L}>d \epsilon_{I m} / d N_{H}, d N_{L} / d \lambda>\right| d N_{H} / d \lambda \mid$ to establish that $d W / d \lambda>0$.

Since $R_{I}$ is independent of $\lambda$,

$$
\frac{d \epsilon_{I k}}{d \lambda}=\frac{1}{M_{I k}} \frac{d M_{I k}}{d \lambda}
$$

From equation (5), with two income classes,

$$
\begin{aligned}
& \frac{1}{M_{I L}} \frac{d M_{I L}}{d \lambda}=\frac{N_{H}}{\lambda\left(\lambda N_{L}+N_{H}\right)} \\
& \frac{1}{M_{I H}} \frac{d M_{I H}}{d \lambda}=\frac{-N_{L}}{\left(\lambda N_{L}+N_{H}\right)} .
\end{aligned}
$$

At $\lambda=M_{A L} / M_{A H}, N_{L}=N_{H}$ since the two income classes are of equal size. Since $\lambda<1$, $d \epsilon_{I L} / d \lambda>\left|d \epsilon_{I H} / d \lambda\right|$ and so the direct effect of an increase in $\lambda$ on $W$ is positive.

$$
\frac{d \epsilon_{I m}}{d N_{k}}=\frac{1}{M_{I m}} \frac{d M_{I m}}{d N_{k}}-\frac{1}{2} \frac{d R_{I}}{d N_{k}} .
$$

We know from Lemma 2 that $d M_{I m} / d N_{k}=0$ when there is no redistribution. We also know from Lemma 2 that $d R_{I} / d N_{k}<0$. We thus need to show that $\left|d R_{I} / d N_{L}\right|>\left|d R_{I} / d N_{H}\right|$.

From equation (15), the required condition is

$$
\frac{V_{A L}}{V_{A H}}>\frac{\left(N_{L}+2 N_{H}\right) \frac{M_{A L}}{M_{A H}}-N_{H}}{\left(2 N_{L}+N_{H}\right)-N_{L} \frac{M_{A L}}{M_{A H}}} .
$$

$V_{A L} / V_{A H}=\left(M_{A L} / M_{A H}\right)^{2}$ because $R_{A L}=R_{A H}$ by assumption. It follows that both the left hand side (LHS) and the right hand side (RHS) of the preceding inequality are increasing and convex functions of $M_{A L} / M_{A H}$. It is straightforward to verify that the LHS starts above the RHS at $M_{A L} / M_{A H}=0$, cuts it from above at $M_{A L} / M_{A H}=N_{H} / N_{L}$, and then converges to the RHS from below at $M_{A L} / M_{A H}=1$. The inequality, LHS $>$ RHS, is thus satisfied for $M_{A L} / M_{A H}<N_{H} / N_{L}$. $N_{L}=N_{H}$ when $\lambda=M_{A L} / M_{A H}$. Since $M_{A L} / M_{A H}<1$ by construction, the preceding condition is always satisfied, ensuring that $\left|d R_{I} / d N_{L}\right|>\left|d R_{I} / d N_{H}\right|$.

To show that $d N_{L} / d \lambda>\left|d N_{H} / \lambda\right|$, apply the Implicit Function theorem to the fixedpoint equation (7), which we know has a unique solution from Lemma 2, to obtain,

$$
\frac{d N_{k}}{d \lambda}=\frac{f\left(\epsilon_{I k}\right) \frac{d \Delta M_{k}}{d \lambda}}{\frac{1}{P_{k}}-f\left(\epsilon_{I k}\right)\left(\frac{d \Delta M_{k}}{d N_{k}}-\frac{1}{2} \frac{d R_{I}}{d N_{k}}\right)}
$$


Recall from Lemma 2 that the slope of the $F$ function is shallower than the slope of the straight line, $1 / P_{k}$, at the fixed-point since it cuts it from above. This implies that the denominator of the preceding equation must be positive for each income class, $k \in\{L, H\}$. When $\lambda=M_{A L} / M_{A H}, f\left(\epsilon_{I L}\right)=f\left(\epsilon_{I H}\right), d \Delta M_{L} / d N_{L}=d \Delta M_{H} / d N_{H}=0$, and as shown above, $\left|d R_{I} / d N_{L}\right|>\left|d R_{I} / d N_{H}\right| . P_{L}=P_{H}$ because income classes are of equal size. This implies that the denominator must be smaller for the low income-class. Turning to the numerator, we showed above that $\frac{d \Delta M_{L}}{d \lambda}>\left|\frac{d \Delta M_{H}}{d \lambda}\right|$ at $\lambda=M_{A L} / M_{A H}$. Since $f\left(\epsilon_{I L}\right)=f\left(\epsilon_{I H}\right)$, the numerator of the preceding equation will be greater for the low income-class (in absolute magnitude), reinforcing the difference in the denominator derived above, to establish that $d N_{L} / d \lambda>\left|d N_{H} / d \lambda\right|$.

The indirect participation effect reinforces the direct effect, implying that $d W / d \lambda$ is unambiguously positive at $\lambda=M_{A L} / M_{A H}$. Thus, there must be redistribution in equilibrium, $\lambda^{*}>M_{A L} / M_{A H}$, to complete the proof.

Proof of Proposition 2 To prove Proposition 2, replace income classes, $k \in\{L, H\}$, with risk classes, $k \in\{R, S\}$, and appropriately relabel key equations and inequalities that were used to prove Proposition 1.

$$
\begin{gathered}
W=\sum_{k=R, S} N_{k} \epsilon_{I k}-P_{k} \int_{0}^{\epsilon_{I k}} \epsilon f(\epsilon) d \epsilon, \\
\frac{d W}{d \lambda}=\sum_{k=R, S}\left[N_{k}-P_{k} \epsilon_{I k} f\left(\epsilon_{I k}\right)\right] \frac{d \epsilon_{I k}}{d \lambda}+\left\{\epsilon_{I k}+\sum_{m=R, S}\left[N_{m}-P_{m} \epsilon_{I m} f\left(\epsilon_{I m}\right)\right] \frac{d \epsilon_{I m}}{d N_{k}}\right\} \frac{d N_{k}}{d \lambda}
\end{gathered}
$$

We assumed when proving Proposition 1 that $M_{A L}<M_{A H}, R_{A L}=R_{A H}$. Since the community is now divided by risk, we assume instead that $R_{A R}>R_{A S}, M_{A R}=M_{A S}$. Without redistribution, $\lambda=M_{A R} / M_{A S}=1 . \Delta M_{R}=\Delta M_{S}=0 . \Delta R_{R}>\Delta R_{S}$. Given that $\epsilon_{I k}=\Delta M_{k}+\Delta R_{k}$, this implies that $\epsilon_{I R}>\epsilon_{I S}$. The epsilon distribution, characterized by the $F$ function, is assumed to be the same in both risk classes. Risk classes are of equal size; $P_{R}=P_{S}$. Since $N_{k}=P_{k} F\left(\epsilon_{I k}\right)$, it follows that $N_{R}>N_{S}$. If the surplus increases with redistribution, we will see below that $\lambda$ can decline only as far as a threshold $\underline{\lambda}$ at which $N_{R}=N_{S} ; \lambda \in[\underline{\lambda}, 1]$. We evaluate $d W / d \lambda$ at $\lambda=1$ and $\lambda=\underline{\lambda}$. We will see that the sign of the derivative is ambiguous at $\lambda=1$ but strictly positive at $\lambda=\underline{\lambda}$.

As with the proof of Proposition 1, we examine $d \epsilon_{I k} / d \lambda, d \epsilon_{I m} / d N_{k}$, and $d N_{k} / d \lambda$, in turn.

$$
\begin{gathered}
\frac{d \epsilon_{I k}}{d \lambda}=\frac{1}{M_{I k}} \frac{d M_{I k}}{d \lambda} . \\
\frac{1}{M_{I R}} \frac{d M_{I R}}{d \lambda}=\frac{N_{S}}{\lambda\left(\lambda N_{R}+N_{S}\right)} \\
\frac{1}{M_{I S}} \frac{d M_{I S}}{d \lambda}=\frac{-N_{R}}{\left(\lambda N_{R}+N_{S}\right)} .
\end{gathered}
$$


Without redistribution, $\lambda=1$ and $N_{R}>N_{S}$. This implies that $d \epsilon_{I R} / d \lambda<\left|d \epsilon_{I S} / d \lambda\right|$. Noting that $N_{k}=P_{k} F\left(\epsilon_{I k}\right)$, it follows that $N_{R}-P_{R} \epsilon_{I R} f\left(\epsilon_{I R}\right)>N_{S}-P_{S} \epsilon_{I S} f\left(\epsilon_{I S}\right)$. The direct effect of an increase in $\lambda$ on $W$ is consequently ambiguous. If the sign of the derivative is positive, $\lambda=1$ and $N_{R}>N_{S}$ in equilibrium. If the sign of the derivative is negative, the surplus can be increased by reducing $\lambda$, but only as long as $N_{R}>N_{S}$. As $\lambda$ declines, the gap between $N_{R}$ and $N_{S}$ declines. At $\underline{\lambda}<1, \epsilon_{I R}=\epsilon_{I S}$ and $N_{R}=N_{S}$. From the equations above, the direct effect is unambiguously positive at $\lambda=\underline{\lambda}$.

$$
\frac{d \epsilon_{I m}}{d N_{k}}=\frac{1}{M_{I m}} \frac{d M_{I m}}{d N_{k}}-\frac{1}{2} \frac{d R_{I}}{d N_{k}} .
$$

From equation (5),

$$
\begin{aligned}
& M_{I k}=\left(\frac{\lambda_{k}}{\sum_{k} \lambda_{k} N_{k}}\right) \sum_{k} N_{k} M_{A k} . \\
& M_{I R}=\left(\frac{\lambda}{\lambda N_{R}+N_{S}}\right)\left(N_{R} M_{A R}+N_{S} M_{A S}\right) \quad M_{I S}=\left(\frac{1}{\lambda N_{R}+N_{S}}\right)\left(N_{R} M_{A R}+N_{S} M_{A S}\right) . \\
& \frac{1}{M_{I R}} \frac{d M_{I R}}{d N_{R}}=\frac{(1-\lambda)}{\left(\lambda N_{R}+N_{S}\right)} \frac{N_{S}}{N_{R}+N_{S}} \quad \frac{1}{M_{I R}} \frac{d M_{I R}}{d N_{S}}=\frac{-(1-\lambda)}{\left(\lambda N_{R}+N_{S}\right)} \frac{N_{R}}{N_{R}+N_{S}} \\
& \frac{1}{M_{I S}} \frac{d M_{I S}}{d N_{R}}=\frac{(1-\lambda)}{\left(\lambda N_{R}+N_{S}\right)} \frac{N_{S}}{N_{R}+N_{S}} \quad \frac{1}{M_{I S}} \frac{d M_{I S}}{d N_{S}}=\frac{-(1-\lambda)}{\left(\lambda N_{R}+N_{S}\right)} \frac{N_{R}}{N_{R}+N_{S}}
\end{aligned}
$$

Without redistribution $(\lambda=1)$ we have already noted that $d \Delta M_{I m} / d N_{k}=0$. With redistribution, the preceding equations indicate that $d \Delta M_{I R} / d N_{R}>d \Delta M_{I R} / d N_{S}, d \Delta M_{I S} / d N_{R}>$ $d \Delta M_{I S} / d N_{S}$.

$$
\frac{d R_{I}}{d N_{k}}=\frac{V_{A k} \sum_{k} N_{k} M_{A k}-2 M_{A k} \sum_{k} N_{k} V_{A k}}{\left(\sum_{k} N_{k} M_{A k}\right)^{3}} .
$$

Given that $M_{A k}$ is the same in all risk-classes, it is straightforward to show that $d R_{I} / d N_{k}<$ 0 . The required condition, from the preceding equation, is

$$
V_{A k}<2 \frac{\sum_{k} N_{k} V_{A k}}{\sum_{k} N_{k}} .
$$

With two risk-classes, the binding condition is

$$
V_{A R}<2 \frac{\left(N_{R} V_{A R}+N_{S} V_{A S}\right)}{\left(N_{R}+N_{S}\right)},
$$

which reduces to

$$
V_{A R}\left(N_{R}-N_{S}\right)+2 N_{S} V_{A S}>0 .
$$

$N_{R} \geq N_{S}$ for $\lambda \in[\underline{\lambda}, 1]$, which implies that this condition is always satisfied.

Given that $d R_{I} / d N_{k}<0$, we can show that $\left|d R_{I} / d N_{R}\right|>\left|d R_{I} / d N_{S}\right|$. The required condition is

$$
\frac{V_{A R}}{V_{A S}}>\frac{\left(N_{R}+2 N_{S}\right) \frac{M_{A R}}{M_{A S}}-N_{S}}{\left(2 N_{R}+N_{S}\right)-N_{R} \frac{M_{A R}}{M_{A S}}},
$$


which is always satisfied since $M_{A R}=M_{A S}$ and $V_{A R}>V_{A S}$.

For $m \in\{R, S\}, d \Delta M_{I m} / d N_{R}=\Delta M_{I m} / d N_{S}=0$ when $\lambda=1 . d \Delta M_{I m} / d N_{R}>$ $d \Delta M_{I m} / d N_{S}$ when $\lambda=\underline{\lambda} .\left|d R_{I} / d N_{R}\right|>\left|d R_{I} / d N_{S}\right|$. Thus, $d \epsilon_{I m} / d N_{R}>d \epsilon_{I m} / d N_{S}$ for $\lambda=1$ and $\lambda=\underline{\lambda}$. When $\lambda=1, \epsilon_{I R}>\epsilon_{I S}$ and $N_{R}-P_{R} \epsilon_{I R} f\left(\epsilon_{I R}\right)>N_{S}-P_{S} \epsilon_{I S} f\left(\epsilon_{I S}\right)$. When $\lambda=\underline{\lambda}, \epsilon_{I R}=\epsilon_{I S}$ and $N_{R}-P_{R} \epsilon_{I R} f\left(\epsilon_{I R}\right)=N_{S}-P_{S} \epsilon_{I S} f\left(\epsilon_{I S}\right)$. The term in curly brackets in the $d W / d \lambda$ equation is thus unambiguously larger for the risky class.

$$
\frac{d N_{k}}{d \lambda}=\frac{f\left(\epsilon_{I k}\right) \frac{d \Delta M_{k}}{d \lambda}}{\frac{1}{P_{k}}-f\left(\epsilon_{I k}\right)\left(\frac{d \Delta M_{k}}{d N_{k}}-\frac{1}{2} \frac{d R_{I}}{d N_{k}}\right)}
$$

At $\lambda=1, \epsilon_{I R}>\epsilon_{I S}, d \Delta M_{k} / d N_{k}=0$, and $\left|d R_{I} / d N_{R}\right|>\left|d R_{I} / d N_{S}\right|$. At $\lambda=\underline{\lambda}$, $\epsilon_{I R}=\epsilon_{I S}, d \Delta M_{R} / d N_{R}>d \Delta M_{S} / d N_{S}$, and $\left|d R_{I} / d N_{R}\right|>\left|d R_{I} / d N_{S}\right|$ The denominator of the right hand side of the preceding equation is unambiguously smaller for the risky class. However, without redistribution, $d \Delta M_{R} / d \lambda<\left|d \Delta M_{S} / d \lambda\right|$. The numerator is not necessarily larger for the risky class. At $\underline{\lambda}$, however, $\epsilon_{I R}=\epsilon_{I S}$, and we saw above that $d \Delta M_{R} / d \lambda>\left|d \Delta M_{S} / d \lambda\right|$. It follows that $d N_{R} / d \lambda>\left|d N_{S} / d \lambda\right|$.

Each term on the right hand side of the $d W / d \lambda$ equation is positive at $\lambda=\underline{\lambda}$. This implies that $\lambda>\underline{\lambda}$ in equilibrium and, hence, that $N_{R}>N_{S}$ to complete the proof. 


\section{References}

[1] Abramitzky, Ran. 2008. The Limits of Equality: Insights from the Israeli Kibbutz, Quarterly Journal of Economics 123(3):1111-1159.

[2] Angelucci, Manuela, Gicomo De Giorgi, and Imran Rasul. 2014. Resource Pooling within Family Networks: Insurance and Investment, University of Michigan typescript.

[3] Banerjee, Abhijit and Andrew Newman. 1998. Information, the Dual Economy, and Development, Review of Economic Studies 65: 631-653.

[4] Buera, Francisco, Joseph P. Kaboski and Yongseok Shin. 2012. Finance and Development: A Tale of Two Sectors, American Economic Review 101(5):1964-2002.

[5] Buera, Francisco and Yongseok Shin. 2013. Financial Frictions and the Persistence of History: A Quantitative Exploration, Journal of Political Economy. 121(2):221-272.

[6] Caldwell, John C., P.H. Reddy, Pat Caldwell. 1986. Periodic High Risk as a Cause of Fertility Decline in a Changing Rural Environment: Survival Strategies in the 19801983 South Indian Drought, Economic Development and Cultural Change 677-701.

[7] Caselli, Francesco. 2005. Accounting for Cross-Country Income Differences, in Handbook of Economic Growth ed. P. Aghion and S. Durlauf.

[8] Chandavarkar, Rajnarayan. 1994. The Origins of Industrial Capitalism in India: Business strategies and the working classes in Bombay, 1900-1940. Cambridge: Cambridge University Press.

[9] Chiquiar, Daniel and Gordon Hanson. 2005. International Migration, Self-Selection, and the Distribution of Wages: Evidence from Mexico and the United States, Journal of Political Economy 113(2): 239-281.

[10] Coate, Stephen and Martin Ravallion. 1993. Reciprocity without Commitment: Characterization and Performance of Informal Insurance Arrangements, Journal of Development Economics 40: 1-24.

[11] Deshingkar, Priya and Edward Anderson. 2004. People on the Move: New Policy Challenges for Increasingly Mobile Populations, Natural Resources Perspectives. Number 92, June. Overseas Development Institute.

[12] Fafchamps, Marcel and Susan Lund. 2003. Risk-Sharing Networks in Rural Philippines, Journal of Development Economics 71(2):261-287. 
[13] Foster, Andrew D. and Mark R. Rosenzweig. 1995. Learning by Doing and Learning from Others: Human Capital and Technical Change in Agriculture, Journal of Political Economy 103(6): 1176-1209.

[14] Foster, Andrew D. and Mark R. Rosenzweig. 2008. Rural Non-Farm Employment Generation and Rural Out- Migration in South Asia, Handbook of Development Economics, Vol. 4, North Holland.

[15] Genicot, Garance and Debraj Ray. 2003. Group Formation in Risk-Sharing Arrangements, Review of Economic Studies 70(1): 87-113.

[16] Gollin, Douglas, David Lagakos, and Michael E. Waugh. 2014. The Agricultural Productivity Gap, Quarterly Journal of Economics, forthcoming.

[17] Grimard, Franque. 1997. Household Consumption Smoothing through Ethnic Ties: Evidence from Cote d'Ivoire, Journal of Development Economics 53(3):319-422.

[18] Harris, John R. and Michael P. Todaro. 1970. Migration, Unemployment and Development: A Two-Sector Analysis, American Economic Review 60(1):126-142.

[19] Hnatkovskay, Viktoria and Amartya Lahiri. 2013. Structural Transformation and the Rural-Urban Divide, University of British Columbia, typescript.

[20] Hsieh, Chang-Tai and Peter J. Klenow. 2009. Misallocation and Ma nufacturing TFP in China and India, Quarterly Journal of Economics 124(4):1403-1448.

[21] Lagos, Ricardo. 2006. A Model of TFP, Review of Economic Studies 73(4):983-1007.

[22] Ligon, Ethan. 1998. Risk-Sharing and Information in Village Economies, Review of Economic Studies 65: 847-864.

[23] Ligon, Ethan, Jonathan P. Thomas and Tim Worrall. 2002. Informal Insurance Arrangements with Limited Commitment: Theory and Evidence from Village Economies, Review of Economic Studies 69:209-244.

[24] Lucas, Robert E.B. and Oded Stark. 1985. Motivations to Remit: Evidence from Botswana, Journal of Political Economy 93(5): 901-918.

[25] Luke, Nancy and Kaivan Munshi. 2011. Women as Agents of Change: Female Income and Mobility in India, Journal of Development Economics 94(1):1-17.

[26] Mazzocco, Maurizio and Shiv Saini. 2012. Testing Efficient Risk-Sharing with Heterogeneous Risk Preferences, American Economic Review 102(1): 428-468. 
[27] McKenzie, David and Hillel Rapoport. 2010. Self-Selection Patterns in Mexico-U.S. Migration: The Role of Migration Networks, Review of Economics and Statistics 92(4): 811-821.

[28] Ministry of Home Affairs. 2011. Rural Urban Distribution of Population (Provisional Population Totals), Census of India 2011.

[29] Morris, Morris David. 1965. The Emergence of an Industrial Labor Force in India: A Study of the Bombay Cotton Mills, 1854-194\%. Berkeley: University of California Press.

[30] Morten, Melanie. 2012. Temporary Migration and Endogenous Risk Sharing in Village India, Stanford University typescript.

[31] Munshi, Kaivan. 2003. "Networks in the Modern Economy: Mexican Migrants in the U.S. Labor Market." Quarterly Journal of Economics, Vol. 118(2), pp. 549-597.

[32] Munshi, Kaivan. 2011. Strength in Numbers: Networks as a Solution to Occupational Traps, Review of Economic Studies 78:1069-1101.

[33] Munshi, Kaivan and Mark R. Rosenzweig. 2006. Traditional Institutions Meet the Modern World: Caste, Gender and Schooling Choice in a Globalizing Economy. American Economic Review 96(4): 1225-1252.

[34] Olken, Benjamin and Monica Singhal. 2011. Informal Taxation, American Economic Journal: Applied Economics 3(4): 1-28.

[35] Parente, Stephen L. and Edward C. Prescott. 1999. Monopoly Rights: A Barrier to Riches, American Economic Review 89(5):1216-1233.

[36] Platteau, Jean-Marie. 2000. Institutions, Social Norms, and Economic Development, Psychology Press.

[37] Restuccia, Diego and Richard Rogerson. 2008. Policy Distortions and AggregateProductivity with Heterogeneous Plants, Review of Economic Dynamics 11:707-720.

[38] Restuccia, Diego, D. T. Yang, and X. Zhu. 2008. Agriculture and Aggregate Productivity: A Quantitative Cross-Country Analysis, Journal of Monetary Economics $55: 234-250$.

[39] Rosenzweig, Mark R. 1978. Rural Wages, Labor Supply, and Land Reform: A Theoretical and Empirical Analysis, American Economic Review 68(5): 847-861.

[40] Rosenzweig, Mark R. and Oded Stark. 1989. Consumption Smoothing, Migration, and Marriage: Evidence from Rural India, Journal of Political Economy 97(4): 905-926. 
[41] Thomas, Duncan, Elizabeth Frankenberg and James P. Smith. 2001. Lost but not forgotten: Attrition and follow-up in the Indonesia Family Life Survey, Journal of Human Resources 36(3): 556-592.

[42] Townsend, Robert. 1994. Risk and Insurance in Village India. Econometrica 62(3):17184 .

[43] Udry, Christopher. 1994. Risk and Insurance in a Rural Credit Market: An Empirical Investigation in Northern Nigeria. Review of Economic Studies 61(3): 495-526.

[44] UNDP. 2002. Deepening Democracy in a Fragmented World. Human Development Report.

[45] Vollrath, Dietrich. 2009. How Important are Dual Economy Effects for Aggregate Productivity? Journal of Development Economics 88(2): 325-334.

[46] Young, Alwyn. 2014. Inequality, the Urban-Rural Gap and Migration, Quarterly Journal of Economics forthcoming. 
Table 1: Rural-Urban Wage Gaps in India in 2004

\begin{tabular}{|c|c|c|c|}
\hline \multirow{3}{*}{ Sector: } & \multicolumn{3}{|c|}{ wage } \\
\hline & nominal & $\begin{array}{c}\text { PPP-adjusted } \\
\text { (rural consumption) }\end{array}$ & $\begin{array}{c}\text { PPP-adjusted } \\
\text { (urban consumption) }\end{array}$ \\
\hline & (1) & $(2)$ & (3) \\
\hline Urban & 62.66 & 54.05 & 57.58 \\
\hline Rural & 42.54 & 42.54 & 42.54 \\
\hline \% gain & 47.30 & 27.06 & 35.35 \\
\hline
\end{tabular}

Source: National Sample Survey.

Wages are measured as daily wages for individuals with less than primary education.

PPP-adjustment is based on rural and urban consumption bundles, respectively, for those individuals. 
Table 2: Participation in the Caste-Based Insurance Arrangement

\begin{tabular}{lccc}
\hline \hline Survey year: & 1982 & & 1999 \\
\cline { 2 - 3 } Households participating (\%) & 25.44 & & 19.62 \\
Income of senders & 5678.92 & & 19956.29 \\
& $(7617.55)$ & & $(22578.95)$ \\
Percent of income sent & 5.28 & 8.74 \\
Income of receivers & 4800.29 & & 10483.84 \\
& $(4462.63)$ & & $(13493.68)$ \\
Percent of income received & 19.06 & & 40.26 \\
Number of observations & 4981 & 7405 \\
\hline \hline
\end{tabular}

Source: Rural Economic Development Survey (REDS) 1982 and 1999.

Standard deviations in parentheses.

Participation in the insurance arrangement includes giving or receiving gifts and loans.

Participation measured over the year prior to each survey round.

Income is measured in 1982 Rupees. 
Table 3: Percent of Loans by Purpose and Source

\begin{tabular}{|c|c|c|c|c|c|c|c|c|c|c|}
\hline \multirow{2}{*}{$\begin{array}{l}\text { Data source: } \\
\text { Purpose: }\end{array}$} & \multicolumn{5}{|c|}{1982 REDS } & \multicolumn{5}{|c|}{2005 IHDS } \\
\hline & $\frac{\text { investment }}{(1)}$ & $\begin{array}{c}\begin{array}{l}\text { operating } \\
\text { expenses }\end{array} \\
(2) \\
\end{array}$ & $\begin{array}{c}\text { contingencies } \\
(3)\end{array}$ & $\begin{array}{c}\begin{array}{c}\text { consumption } \\
\text { expenses }\end{array} \\
(4) \\
\end{array}$ & $\begin{array}{l}\text { all } \\
(5) \\
\end{array}$ & $\frac{\text { investment }}{(6)}$ & $\begin{array}{c}\begin{array}{r}\text { operating } \\
\text { expenses }\end{array} \\
(7) \\
\end{array}$ & $\begin{array}{c}\text { contingencies } \\
(8)\end{array}$ & $\begin{array}{c}\begin{array}{c}\text { consumption } \\
\text { expenses }\end{array} \\
(9) \\
\end{array}$ & $\begin{array}{c}\text { all } \\
(10) \\
\end{array}$ \\
\hline Share: & 0.15 & 0.60 & 0.13 & 0.07 & 1.00 & 0.25 & 0.46 & 0.21 & 0.04 & 1.00 \\
\hline$\frac{\text { Source: }}{\text { Bank }}$ & 64.11 & 80.80 & 27.58 & 25.12 & 64.61 & 46.79 & 62.49 & 18.78 & 19.82 & 46.70 \\
\hline Caste & 16.97 & 6.07 & 42.65 & 23.12 & 13.87 & 7.82 & 4.11 & 19.64 & 14.24 & 9.12 \\
\hline Friends & 2.11 & 11.29 & 2.31 & 4.33 & 7.84 & 6.01 & 3.33 & 8.28 & 7.09 & 5.38 \\
\hline Employer & 5.08 & 0.49 & 21.15 & 15.22 & 5.62 & 3.31 & 0.54 & 1.11 & 1.85 & 1.23 \\
\hline Moneylender & 11.64 & 1.27 & 5.05 & 31.85 & 7.85 & 20.69 & 12.82 & 46.80 & 53.65 & 24.67 \\
\hline Other & 0.02 & 0.07 & 1.27 & 0.37 & 0.22 & 15.38 & 16.71 & 5.39 & 3.35 & 12.90 \\
\hline Total & 100.00 & 100.00 & 100.00 & 100.00 & 100.00 & 100.00 & 100.00 & 100.00 & 100.00 & 100.00 \\
\hline
\end{tabular}

Source: 1982 Rural Economic Development Survey (REDS) and 2005 India Human Development Survey (IHDS).

Statistics are weighted by the value of the loan and sample weights.

Columns 1-5 computed using 982 loans receivedin the year prior to the 1982 survey round.

Column 6-10 computed using 12,066 rural loans received in the year prior to the 2005 IHDS.

IHDS 2005 reports loans received from relatives rather than caste.

Investment includes land, house, business, etc.

Operating expenses are for agricultural production.

Contingencies include marriage, illness, etc.

Other category not reported for Purpose. 
Table 4: Percent of Loans by Type and Source

\begin{tabular}{|c|c|c|c|c|}
\hline Data source: & \multicolumn{3}{|c|}{1982 REDS } & \multirow{2}{*}{$\begin{array}{c}2005 \text { IHDS } \\
\text { without interest } \\
(4)\end{array}$} \\
\hline Loan type: & $\frac{\text { without interest }}{\text { (1) }}$ & $\frac{\text { without collateral }}{(2)}$ & $\begin{array}{c}\begin{array}{c}\text { without collateral or } \\
\text { interest }\end{array} \\
\text { (3) }\end{array}$ & \\
\hline \multicolumn{5}{|l|}{ Source: } \\
\hline Bank & 0.57 & 23.43 & 0.38 & 0.00 \\
\hline Caste & 28.99 & 60.27 & 20.38 & 44.62 \\
\hline Friends & 9.35 & 91.72 & 3.89 & 21.5 \\
\hline Employer & 0.44 & 65.69 & 0.44 & 10.75 \\
\hline Moneylender & 0.00 & 98.71 & 0.00 & 0.27 \\
\hline
\end{tabular}

Source: 1982 Rural Economic Development Survey (REDS) and 2005 India Human Development Survey (IHDS).

Statistics are weighted by the value of the loan and sample weights.

Columns 1-3 computed using 982 loans received in the year prior to the 1982 survey round.

Column 4 computed using 12,066 rural loans received in the 5 years prior to the 2005 IHDS.

IHDS 2005 reports loans received from relatives rather than caste.

The reference category is caste loans. 
Table 5: Income and Consumption within the Caste

\begin{tabular}{|c|c|c|c|c|c|c|c|c|}
\hline \multirow{3}{*}{\multicolumn{2}{|c|}{ Data Source: }} & \multicolumn{3}{|c|}{ ICRISAT } & \multicolumn{4}{|c|}{ REDS 2006} \\
\hline & & $\begin{array}{l}\text { relative } \\
\text { income }\end{array}$ & $\begin{array}{c}\text { relative } \\
\text { consumption }\end{array}$ & $\begin{array}{c}\text { consumption-income } \\
\text { ratio }\end{array}$ & $\begin{array}{l}\text { relative } \\
\text { income }\end{array}$ & $\begin{array}{c}\text { relative } \\
\text { consumption }\end{array}$ & $\begin{array}{l}\text { consumption-income } \\
\text { ratio }\end{array}$ & migration \\
\hline & & $(1)$ & $(2)$ & $(3)$ & (4) & $(5)$ & $(6)$ & $(7)$ \\
\hline \multicolumn{9}{|c|}{ Relative Income class: } \\
\hline & 1 & 0.119 & 0.460 & 3.871 & 0.316 & 0.843 & 2.665 & 0.032 \\
\hline & 2 & 0.281 & 0.625 & 2.224 & 0.416 & 0.854 & 2.052 & 0.034 \\
\hline & 3 & 0.373 & 0.626 & 1.680 & 0.513 & 0.871 & 1.697 & 0.051 \\
\hline & 4 & 0.510 & 0.673 & 1.319 & 0.627 & 0.887 & 1.413 & 0.046 \\
\hline & 5 & 1.000 & 1.000 & 1.000 & 1.000 & 1.000 & 1.000 & 0.051 \\
\hline
\end{tabular}

Note: Income classes are defined by quintiles within each caste.

Income and consumption are measured relative to the highest (fifth) income class.

REDS 2006 income and consumption are inputted from ICRISAT data.

REDS data consists of 100 castes, while ICRISAT data consist of 7 castes.

Sample-size restriction is at least 30 households per caste with REDS data and 20 households per caste with ICRISAT data. 


\section{Table 6: Reduced-Form Migration Estimates}

\begin{tabular}{|c|c|c|c|c|c|c|}
\hline \multirow[t]{2}{*}{ Dependent variable: } & \multicolumn{6}{|c|}{ migration } \\
\hline & $(1)$ & $(2)$ & $(3)$ & (4) & $(5)$ & $(6)$ \\
\hline Household Income & $\begin{array}{c}0.0059 \\
(0.0024)\end{array}$ & $\begin{array}{c}0.0051 \\
(0.0024)\end{array}$ & $\begin{array}{c}0.0026 \\
(0.0045)\end{array}$ & $\begin{array}{c}0.0025 \\
(0.0035)\end{array}$ & $\begin{array}{c}0.0020 \\
(0.0032)\end{array}$ & $\begin{array}{c}0.0021 \\
(0.0036)\end{array}$ \\
\hline Caste Income & $\begin{array}{c}-0.016 \\
(0.0043)\end{array}$ & $\begin{array}{c}-0.018 \\
(0.0055)\end{array}$ & $\begin{array}{l}-0.022 \\
(0.010)\end{array}$ & $\begin{array}{c}-0.027 \\
(0.0082)\end{array}$ & $\begin{array}{c}-0.028 \\
(0.0090)\end{array}$ & $\begin{array}{l}-0.017 \\
(0.014)\end{array}$ \\
\hline Income Risk & -- & $\begin{array}{l}-0.00038 \\
(0.00015)\end{array}$ & $\begin{array}{l}-0.00037 \\
(0.00013)\end{array}$ & $\begin{array}{l}-0.00056 \\
(0.00014)\end{array}$ & $\begin{array}{l}-0.00056 \\
(0.00015)\end{array}$ & $\begin{array}{l}-0.00053 \\
(0.00011)\end{array}$ \\
\hline Village Income & & & $\begin{array}{c}0.007 \\
(0.013)\end{array}$ & $\begin{array}{c}0.007 \\
(0.010)\end{array}$ & $\begin{array}{l}-- \\
--\end{array}$ & $\begin{array}{l}-- \\
--\end{array}$ \\
\hline Village/ Caste Income & & & & & $\begin{array}{l}0.0076 \\
(0.012)\end{array}$ & $\begin{array}{l}0.0088 \\
(0.028)\end{array}$ \\
\hline Village Fixed Effects & No & No & No & No & No & Yes \\
\hline Infrastructure Variables & No & No & No & Yes & Yes & No \\
\hline \multicolumn{7}{|c|}{ Joint sig. of infrastructure variables: } \\
\hline$\chi^{2}$ & $\begin{array}{l}-- \\
--\end{array}$ & -- & $\begin{array}{l}-- \\
--\end{array}$ & $\begin{array}{c}16.14 \\
{[0.0011]}\end{array}$ & $\begin{array}{c}16.59 \\
{[0.00090]}\end{array}$ & -- \\
\hline Number of observations & 19,362 & 19,362 & 19,362 & 19,362 & 19,362 & 19,362 \\
\hline
\end{tabular}

Source: 2006 Rural Economic Development Survey (REDS) census.

Bootstrapped standard errors in parentheses are clustered at the caste level.

Income measured in lakhs of Rupees, (1 lakh $=100,000)$.

$\mathrm{N}$ is the number of households in each caste.

Infrastructure variables : whether there is a bank, secondary school, and health center in the village.

chi-square p-value reported in square brackets

Sample-size restricted to castes with at least 30 households. 
Table 7: Structural Estimates

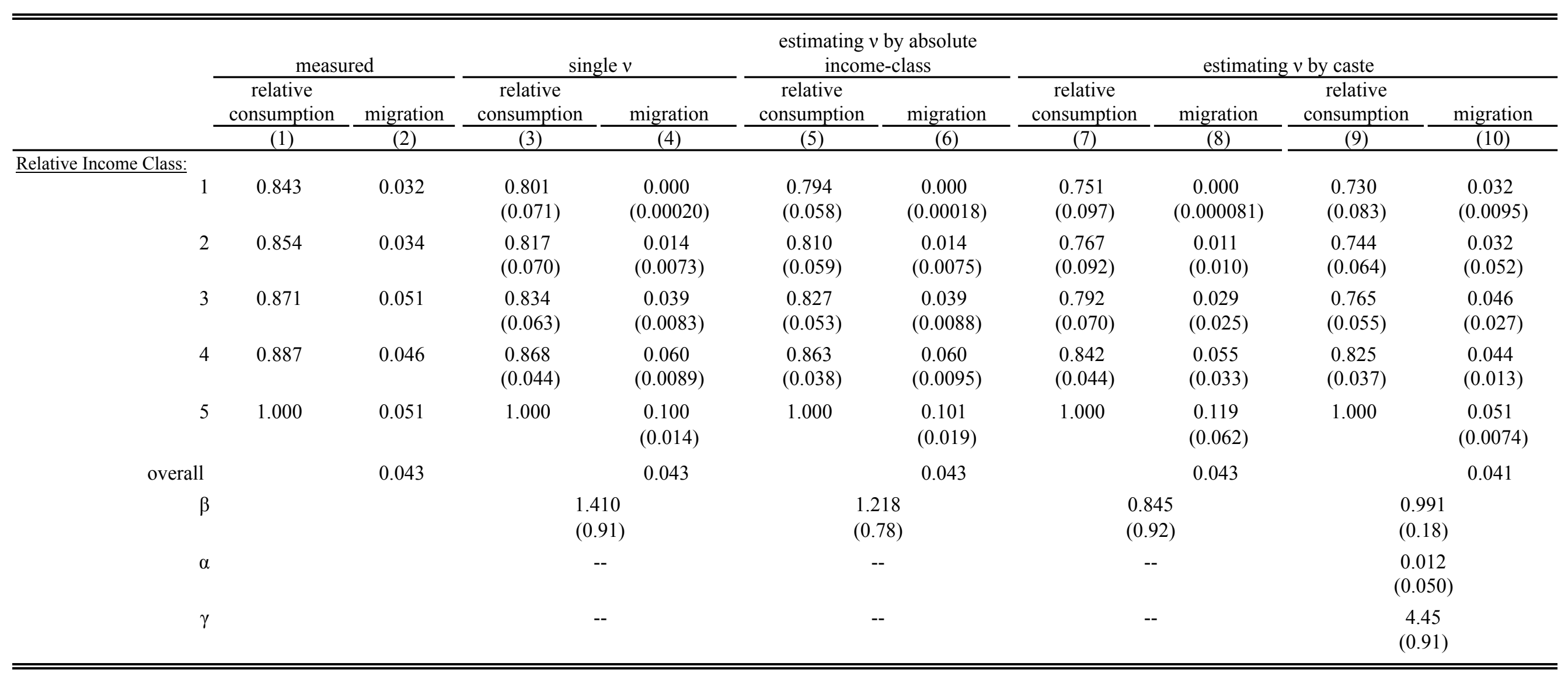

Source: 2006 Rural Economic Development Survey (REDS) census.

Structural estimation is based on 100 castes with at least 30 households in the census.

Relative income classes are defined by quintiles within each caste.

Consumption is measured relative to the highest (fifth) income class in Columns 1, 3, 5, 7, and 9.

Relative consumption and migration are computed as the average in each income-class across all castes.

Jackknifed standard errors in parentheses.

We match on two moments - migration in the lowest and the highest relative income class - in the flexible specification (Columns 9-10).

Standard errors for those two income classes in Column 10 thus reflect sampling error due to the jack-knife procedure.

$\beta=\alpha+\gamma \mathrm{M}_{\mathrm{ak}}$ in Columns 9-10. The estimated $\alpha$ and $\gamma$ parameters are used to compute $\beta$ for the representative household with mean-wealth in the REDS census. 
Table 8: FE-IV Migration, Participation, and Out-Marriage Estimates

\begin{tabular}{lcccc}
\hline \hline Data source: & \multicolumn{3}{c}{ 1982 REDS } \\
\cline { 2 - 3 } Dependent variable: & migration & & out-marriage & participation \\
\cline { 2 - 3 } Household income & $(1)$ & $(2)$ & $(3)$ \\
\hline Caste income & 0.262 & & 0.166 & -0.520 \\
& $(0.172)$ & & $(0.074)$ & $(0.680)$ \\
Time trend & -0.110 & & -0.111 & 0.327 \\
& $(0.045)$ & $(0.066)$ & $(0.139)$ \\
Kleibergen-Paap F-statistic & 0.059 & & 0.026 & 0.014 \\
Hansen J-statistic & $(0.022)$ & $(0.018)$ & $(0.127)$ \\
& 10.52 & 8.05 & 2.91 \\
Number of observations & 2.62 & & 6.74 & 4.17 \\
\hline \hline
\end{tabular}

Source: Rural Economic Development Survey (REDS) panel, 1982 and 1999

Standard errors in parentheses are robust to clustering at the state level.

Income is constructed using wealth- and wage-based measure.

Income measured in lakhs of Rupees, (1 lakh $=100,000)$.

Additional regressors: whether anyone in the village used HYV and share of village land irrigated in 1971 (household and caste average).

Excluded variables: inherited land, interaction of any HYV and irrigation share, interaction of inherited land, any HYV and irrigation share (household and caste average).

Sample restricted to castes with at least 10 households in the panel and households with heads at least age 18 in 1982.

Hansen J-statistic (chi-squared) p-values are reported in square brackets.

Stock-Yogo weak ID test: $5 \%$ critical value $15.72,10 \%$ critical value 9.48 . 


\section{Table A1: Rural-Urban Wage Gaps in India over Time}

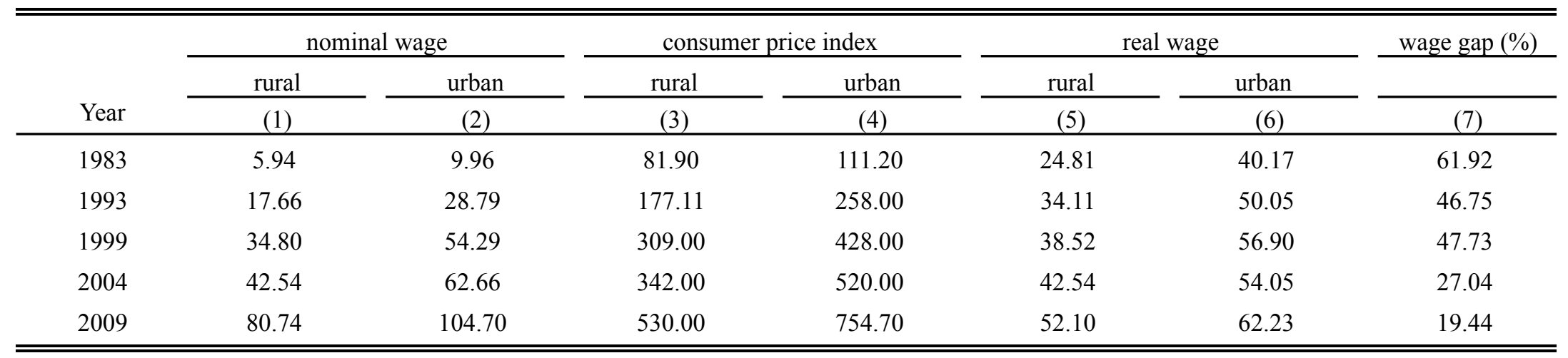

Source: Nominal wage per day is derived from NSS.

Consumer Price Index (CPI) is based on Government of India statistics.

Conversion to real wage in 2004 is based on representative rural consumption bundle in that year.

CPI is used to adjust wages in other years. 
Table A2: Loan Characteristics by Source

\begin{tabular}{|c|c|c|}
\hline \multirow[t]{3}{*}{ Dependent Variable: } & \multicolumn{2}{|c|}{ loan type } \\
\hline & without interest & without collateral \\
\hline & $(1)$ & (2) \\
\hline \multirow[t]{2}{*}{ Bank } & -0.243 & -0.329 \\
\hline & $(0.021)$ & $(0.037)$ \\
\hline \multirow{2}{*}{ Friends } & -0.058 & 0.127 \\
\hline & $(0.041)$ & $(0.072)$ \\
\hline \multirow[t]{2}{*}{ Employer } & -0.227 & 0.009 \\
\hline & $(0.030)$ & $(0.052)$ \\
\hline \multirow[t]{2}{*}{ Moneylender } & -0.247 & -0.005 \\
\hline & $(0.025)$ & $(0.044)$ \\
\hline \multirow[t]{2}{*}{ Other } & 0.075 & 0.206 \\
\hline & $(0.061)$ & $(0.108)$ \\
\hline Number of Observations & 1045 & 1045 \\
\hline
\end{tabular}

Note: The other categories are not reported.

observations are weighted by the value of the loan and sample weights. 
Table A3: Household Characteristics, Income-gain, Migration rate and v parameter by Absolute Income-Classes

\begin{tabular}{|c|c|c|c|c|c|c|c|}
\hline & $\begin{array}{c}\text { household } \\
\text { income }\end{array}$ & land value & $\begin{array}{c}\text { number of } \\
\text { working adults } \\
\end{array}$ & $\begin{array}{c}\text { education of } \\
\text { household head }\end{array}$ & $\begin{array}{c}\text { income-gain from } \\
\text { migration }\end{array}$ & migration rate & $v$ parameter \\
\hline & $(1)$ & $(2)$ & (3) & $(4)$ & (5) & $(6)$ & $(7)$ \\
\hline \multicolumn{8}{|l|}{ Absolute Income class: } \\
\hline & 0.023 & 38084.74 & 1.462 & 4.684 & 0.218 & 0.043 & 19.609 \\
\hline & 0.040 & 35956.19 & 1.451 & 3.909 & 0.228 & 0.010 & 27.352 \\
\hline & 0.051 & 114863.00 & 1.656 & 3.744 & 0.179 & 0.024 & 28.030 \\
\hline & 0.100 & 129849.50 & 1.777 & 5.083 & 0.190 & 0.051 & 21.576 \\
\hline & 0.894 & 90414.75 & 1.950 & 4.741 & 0.166 & 0.026 & 27.329 \\
\hline
\end{tabular}

Source: 2006 Rural Economic Development Survey (REDS) census.

Absolute income classes are defined by quintiles across the entire income distribution, without regard to caste affiliation.

Household income based on assets, number of working adults, education (from REDS) and rural, urban wages (from NSS).

Income-gain is computed assuming a single member of the household migrates.

Migration rate is obtained from the REDS, and together with the income-gain from migration, is used to derive the $v$ parameter 
Table A4: Structural Estimates with 4 and 6 Relative Income-Classes

\begin{tabular}{|c|c|c|c|c|c|c|c|c|c|}
\hline \multirow[t]{4}{*}{$\begin{array}{l}\text { Number of relative } \\
\text { income-classes: }\end{array}$} & & \multicolumn{4}{|c|}{ four } & \multicolumn{4}{|c|}{ six } \\
\hline & & \multicolumn{2}{|c|}{ measured } & \multicolumn{2}{|c|}{ estimated } & \multicolumn{2}{|c|}{ measured } & \multicolumn{2}{|c|}{ estimated } \\
\hline & & $\begin{array}{c}\text { relative } \\
\text { consumption }\end{array}$ & migration & $\begin{array}{c}\text { relative } \\
\text { consumption }\end{array}$ & migration & $\begin{array}{c}\text { relative } \\
\text { consumption }\end{array}$ & migration & $\begin{array}{c}\text { relative } \\
\text { consumption }\end{array}$ & migration \\
\hline & & $(1)$ & $(2)$ & (3) & (4) & $(5)$ & $(6)$ & $(7)$ & $(8)$ \\
\hline \multicolumn{10}{|l|}{ Relative Income class: } \\
\hline & 1 & 0.857 & 0.031 & $\begin{array}{c}0.817 \\
(0.059)\end{array}$ & $\begin{array}{c}0.000 \\
(0.0008)\end{array}$ & 0.831 & 0.033 & $\begin{array}{c}0.785 \\
(0.052)\end{array}$ & $\begin{array}{c}0.000 \\
(0.0000)\end{array}$ \\
\hline & 2 & 0.880 & 0.042 & $\begin{array}{c}0.837 \\
(0.058)\end{array}$ & $\begin{array}{c}0.022 \\
(0.0084)\end{array}$ & 0.837 & 0.027 & $\begin{array}{c}0.797 \\
(0.052)\end{array}$ & $\begin{array}{c}0.013 \\
(0.0073)\end{array}$ \\
\hline & 3 & 0.894 & 0.048 & $\begin{array}{c}0.866 \\
(0.044)\end{array}$ & $\begin{array}{c}0.051 \\
(0.0077)\end{array}$ & 0.854 & 0.050 & $\begin{array}{c}0.812 \\
(0.049)\end{array}$ & $\begin{array}{c}0.025 \\
(0.0106)\end{array}$ \\
\hline & 4 & 1.000 & 0.050 & 1.000 & $\begin{array}{c}0.097 \\
(0.0138)\end{array}$ & 0.854 & 0.047 & $\begin{array}{c}0.829 \\
(0.045)\end{array}$ & $\begin{array}{c}0.043 \\
(0.0110)\end{array}$ \\
\hline & 5 & -- & -- & -- & -- & 0.883 & 0.047 & $\begin{array}{c}0.867 \\
(0.037)\end{array}$ & $\begin{array}{c}0.064 \\
(0.0102)\end{array}$ \\
\hline & 6 & -- & -- & -- & -- & 1.000 & 0.053 & 1.000 & $\begin{array}{c}0.113 \\
(0.0178)\end{array}$ \\
\hline & & & 0.043 & & $\begin{array}{c}0.043 \\
(0.0060)\end{array}$ & & 0.043 & & $\begin{array}{c}0.043 \\
(0.0063)\end{array}$ \\
\hline & $\beta$ & & & $\begin{array}{l}1.3 \\
(0.8\end{array}$ & & & & $\begin{array}{r}1.4 \\
(0.8\end{array}$ & \\
\hline
\end{tabular}

Source: 2006 Rural Economic Development Survey (REDS) census.

Structural estimation is based on 100 castes with at least 30 households in the census.

Four and six equal-sized income classes are constructed within each caste.

benchmark specification (single $\mathrm{v}$ ) in all estimations.

Consumption is measured relative to the highest income class in Column 1 and Column 5.

Relative consumption and migration are computed as the average in each relative income-class across all castes.

Jackknifed standard errors in parentheses. 
Table A5: First-Stage Estimates

\begin{tabular}{|c|c|c|}
\hline Dependent variable: & $\begin{array}{c}\begin{array}{c}\text { hh income } \\
\text { change }\end{array} \\
\text { (1) }\end{array}$ & $\begin{array}{c}\begin{array}{c}\text { caste income } \\
\text { change }\end{array} \\
(2)\end{array}$ \\
\hline Anyone in the village used HYV (household) & $\begin{array}{l}-2787.65 \\
(3719.06)\end{array}$ & $\begin{array}{c}20369.17 \\
(17642.30)\end{array}$ \\
\hline Anyone in the village used HYV (caste average) & $\begin{array}{l}-3348.87 \\
(4990.63)\end{array}$ & $\begin{array}{l}-42467.91 \\
(39691.53)\end{array}$ \\
\hline Share of village land irrigated (household) & $\begin{array}{c}-56.24 \\
(4063.92)\end{array}$ & $\begin{array}{l}5578.18 \\
(9886.26)\end{array}$ \\
\hline Share of village land irrigated (caste average) & $\begin{array}{l}-4094.89 \\
(3144.29)\end{array}$ & $\begin{array}{l}-22929.07 \\
(32659.12)\end{array}$ \\
\hline HYV*irrigation share (household) & $\begin{array}{c}1844.46 \\
(5847.23)\end{array}$ & $\begin{array}{l}-26942.14 \\
(22377.58)\end{array}$ \\
\hline $\mathrm{HYV} *$ irrigation share (caste average) & $\begin{array}{l}-1646.46 \\
(6428.40)\end{array}$ & $\begin{array}{c}24413.53 \\
(45272.26)\end{array}$ \\
\hline inherited land (household) & $\begin{array}{c}3.48 \\
(1.12)\end{array}$ & $\begin{array}{l}-5.32 \\
(4.55)\end{array}$ \\
\hline inherited land (caste average) & $\begin{array}{c}6.48 \\
(7.88)\end{array}$ & $\begin{array}{c}24.11 \\
(43.01)\end{array}$ \\
\hline HYV*irrigation share*inherited land (household) & $\begin{array}{c}3.44 \\
(6.06)\end{array}$ & $\begin{array}{c}6.58 \\
(14.78)\end{array}$ \\
\hline $\mathrm{HYV}^{*}$ irrigation share*inherited land (caste average) & $\begin{array}{c}41.09 \\
(19.56)\end{array}$ & $\begin{array}{l}140.68 \\
(37.31)\end{array}$ \\
\hline Constant & $\begin{array}{l}8084.81 \\
(2828.20)\end{array}$ & $\begin{array}{l}25683.28 \\
(20544.49)\end{array}$ \\
\hline $\begin{array}{l}\text { F statistic (excluded variables) } \\
\text { p-value }\end{array}$ & $\begin{array}{c}104.96 \\
0.00\end{array}$ & $\begin{array}{c}12.28 \\
0.00\end{array}$ \\
\hline R-squared & 0.02 & 0.07 \\
\hline Number of observations & 2335 & 2335 \\
\hline
\end{tabular}

Standard errors in parentheses are robust to clustering at the state level.

Dependent variables are computed as the change between 1982 and 1999.

Income is constructed using a wealth-based measure.

Excluded variables: $\mathrm{HYV}^{*}$ irrigation, inherited land, $\mathrm{HYV}^{*}$ irrigation*inherited land (household and caste average)

Regressions restricted to castes with at least 10 households in sample and households with heads at least age 18 in 1982. 
Figure 1. Rural-Urban Wage Gap, by Country

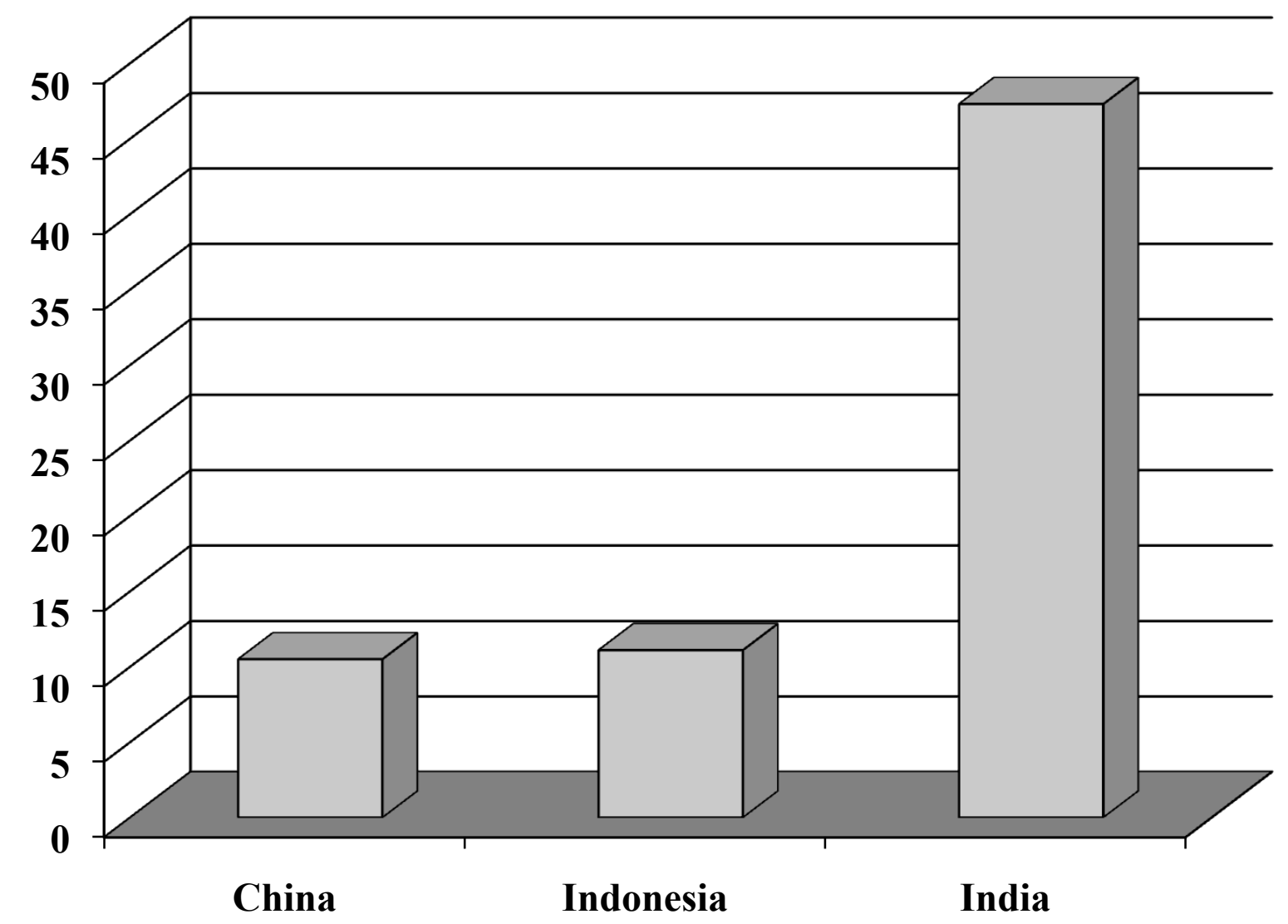


Figure 2. Real Rural and Urban Wages in India

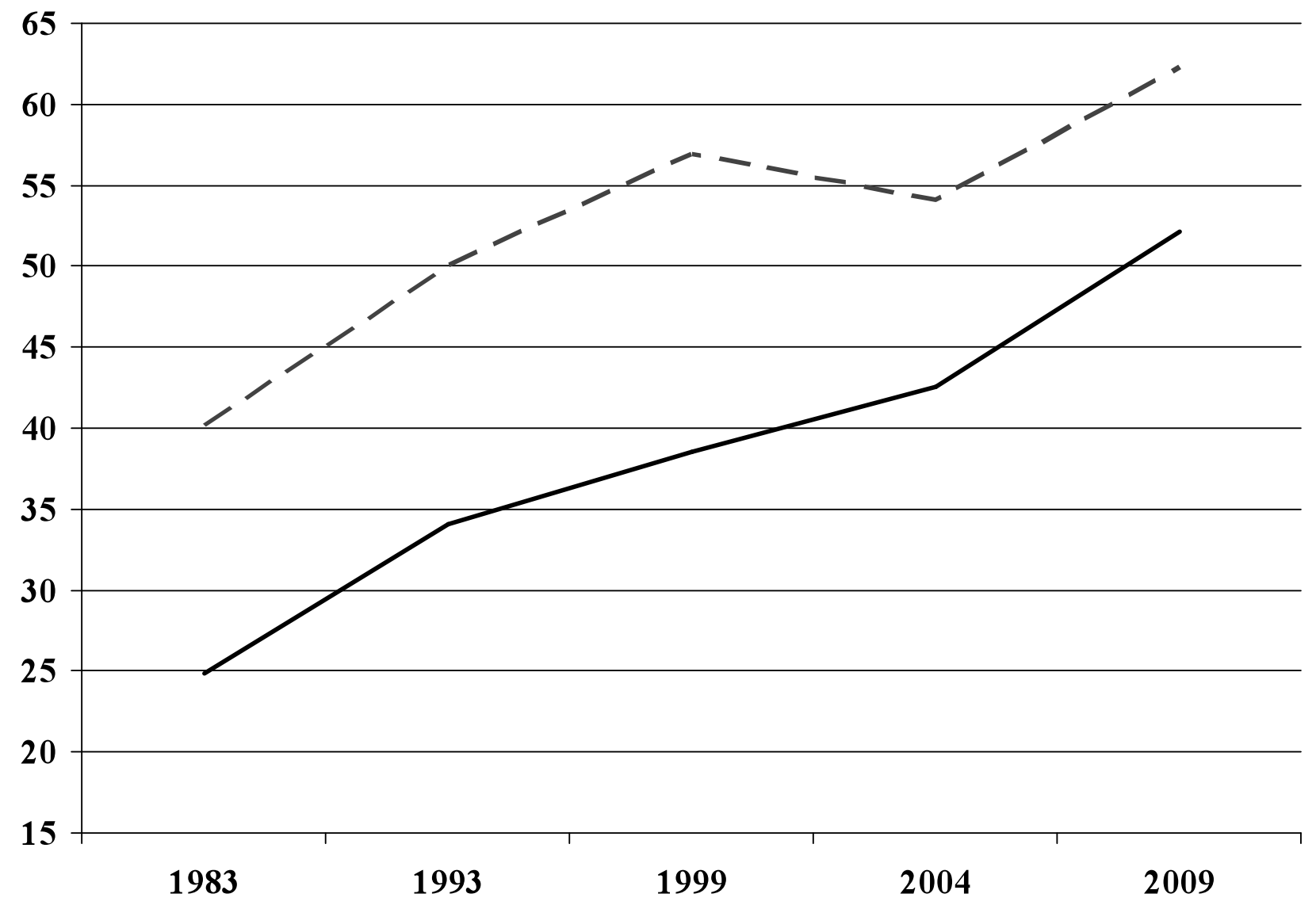


Figure 3. Change in Rural-Urban Migration Rates in India, 1961- 2001

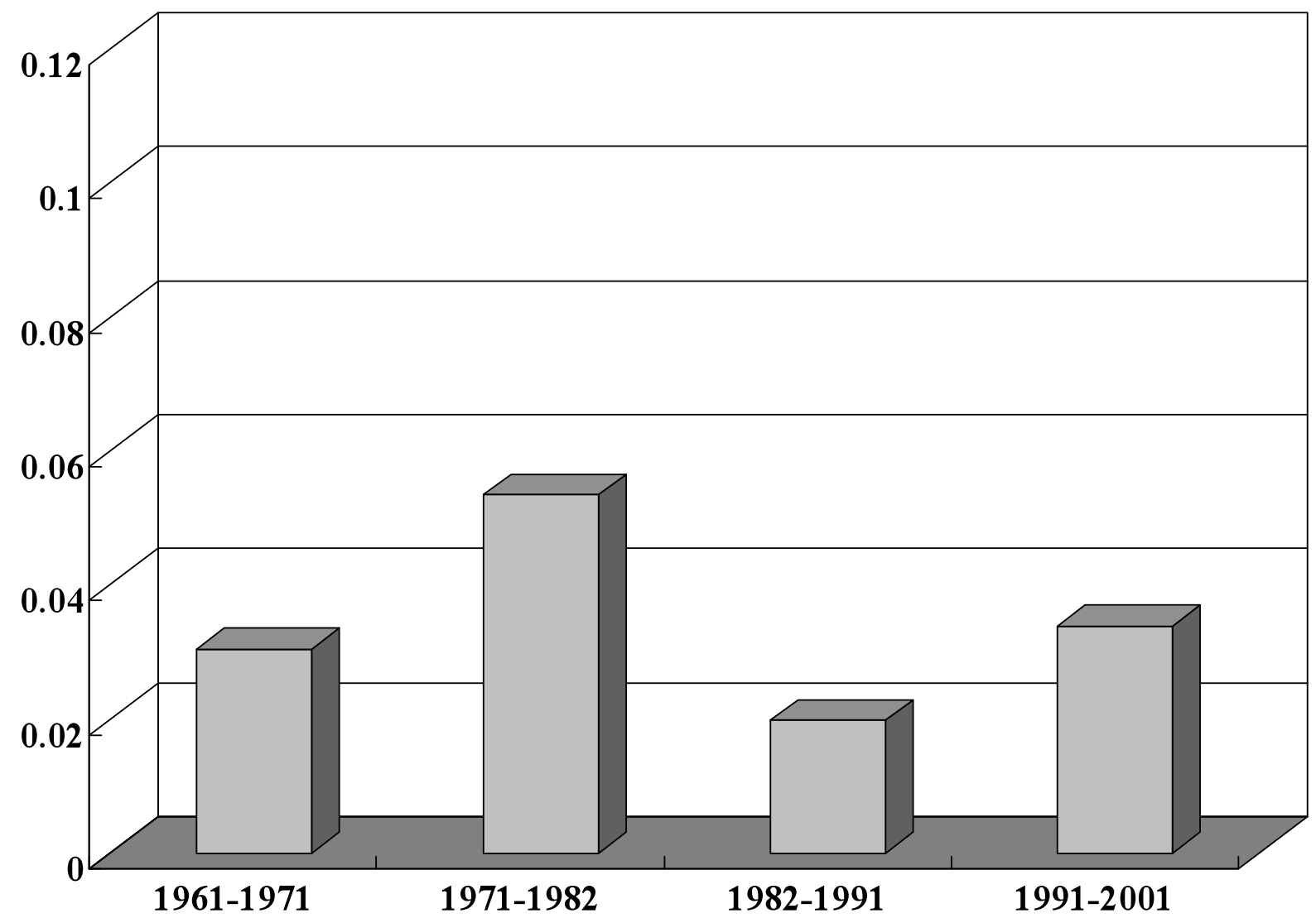


Figure 4. Change in Percent Urbanized, by Country, 1975-2000

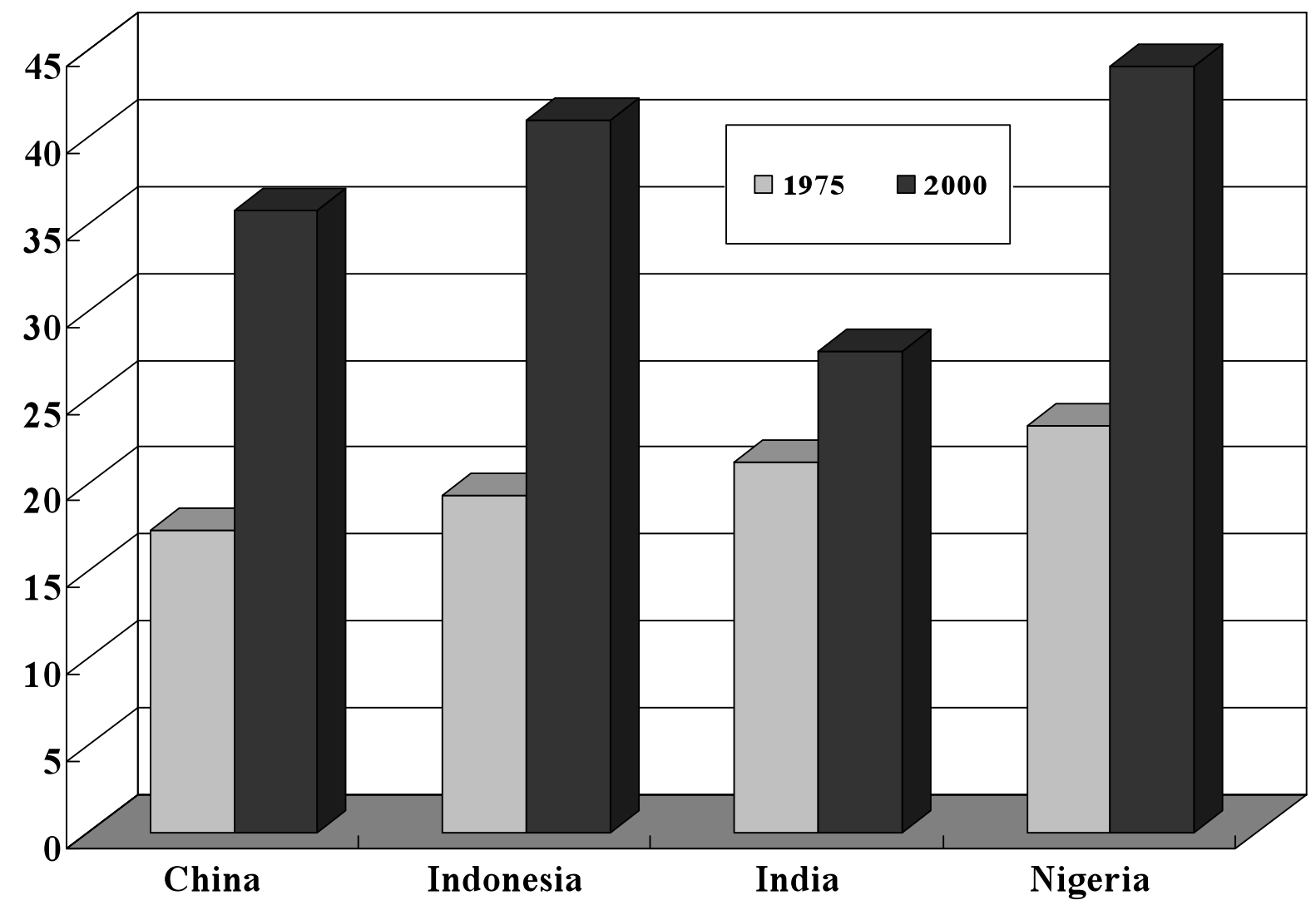


Figure 5. Change in Out-Marriage Percent in Rural India, 1950- 1999

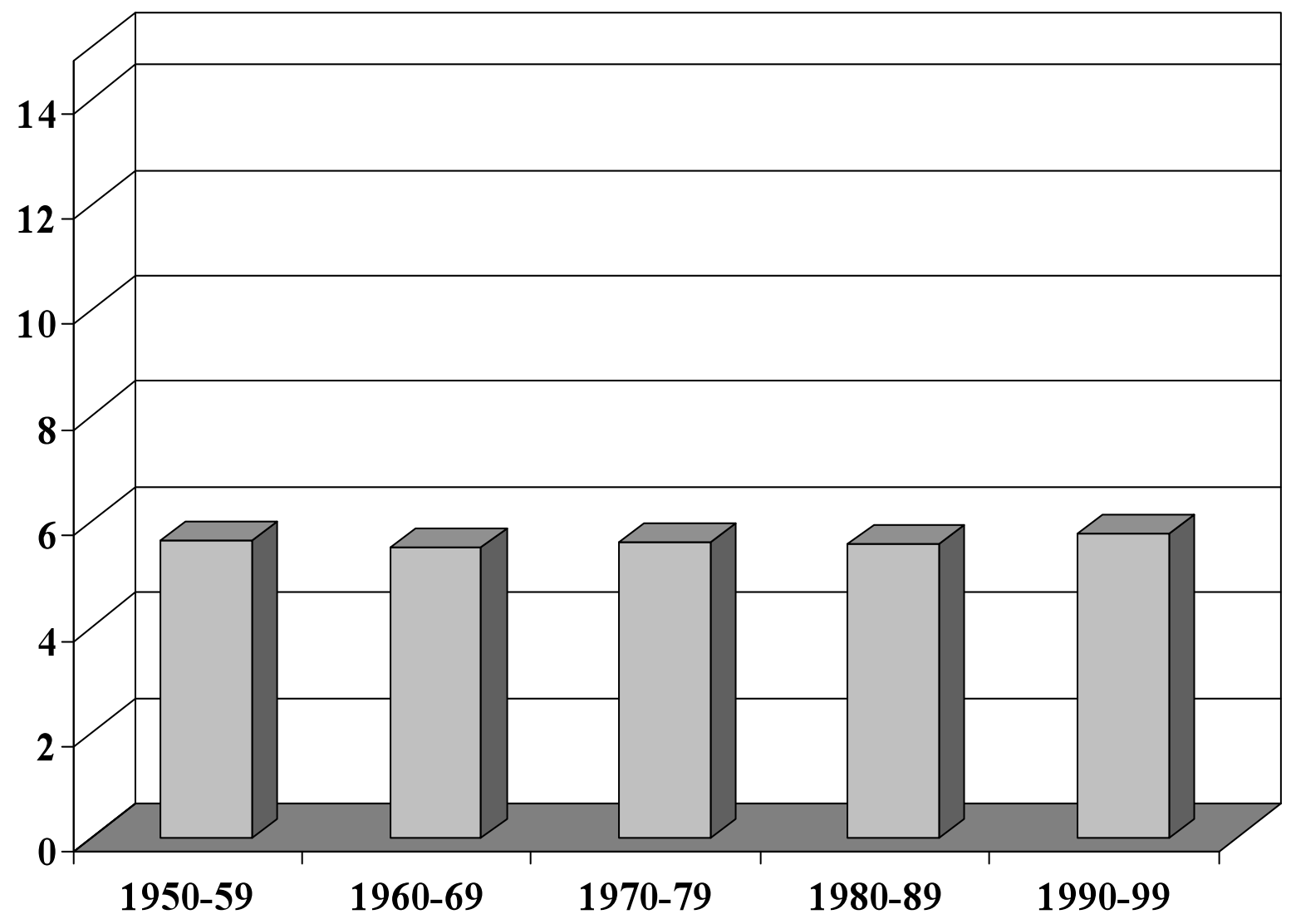


Figure 6. Counter-Factual Simulation

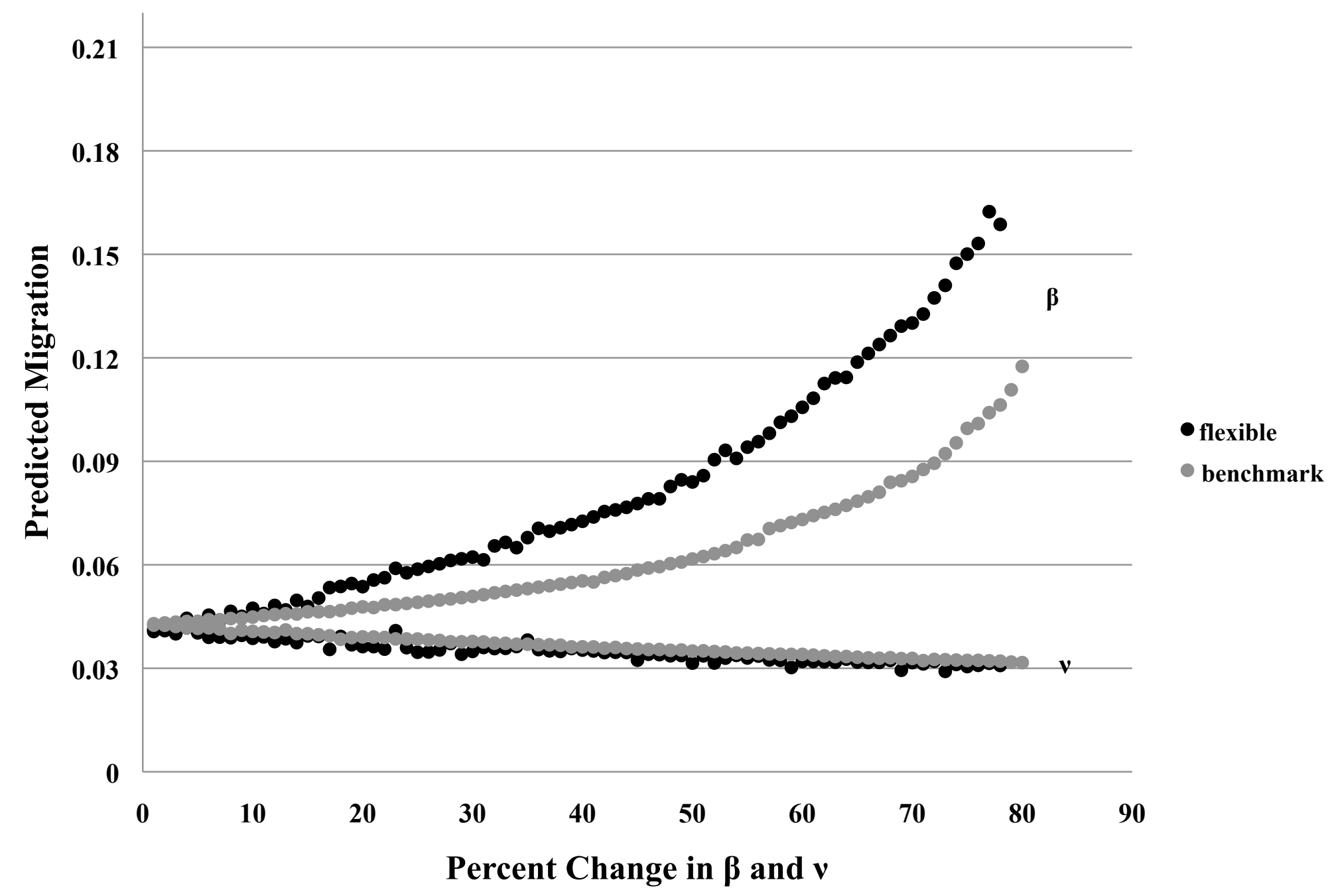


Figure 7. Reducing Risk in Higher Income-classes

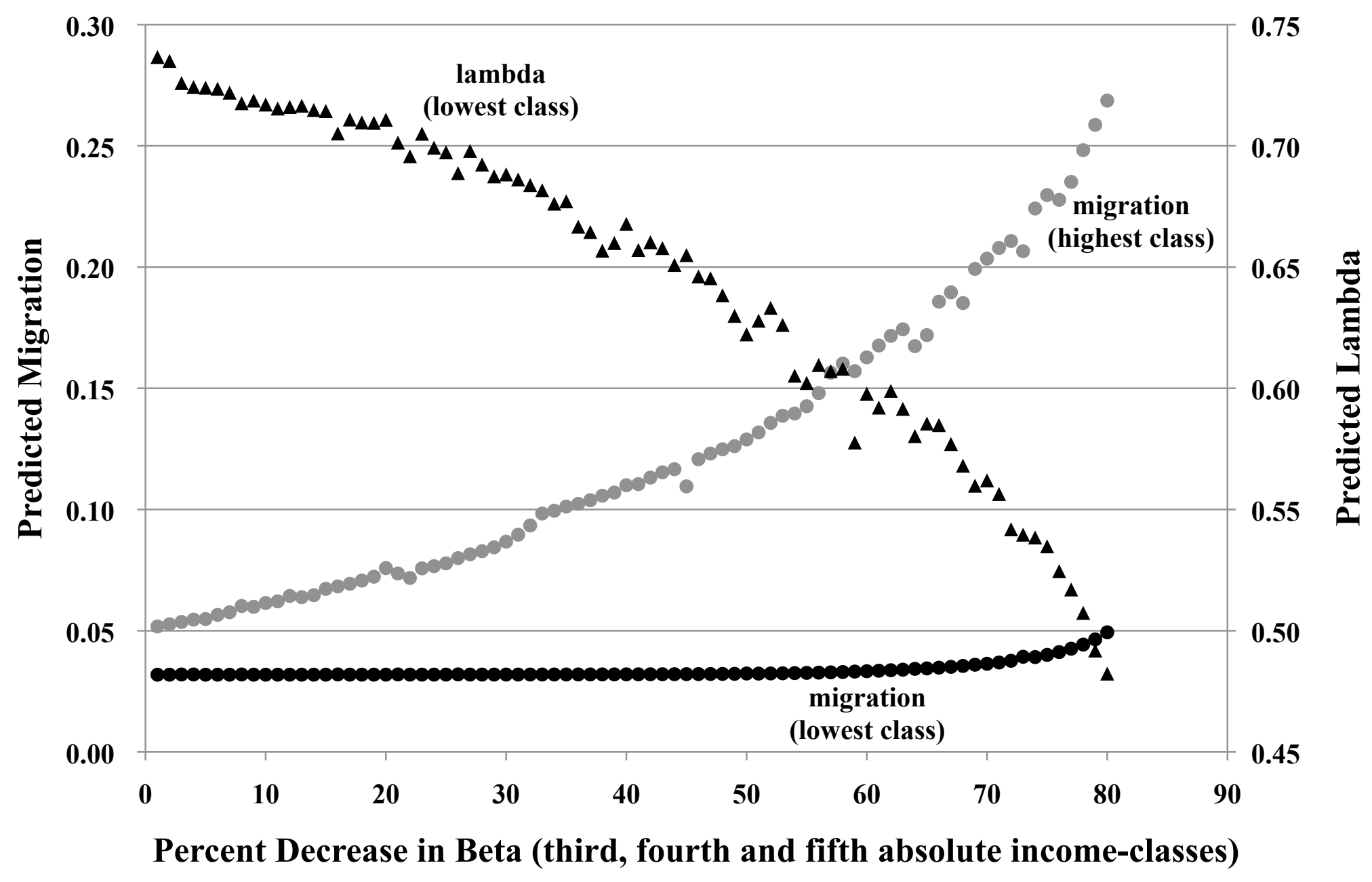


Figure 8. Reducing Risk in Lower Income-classes

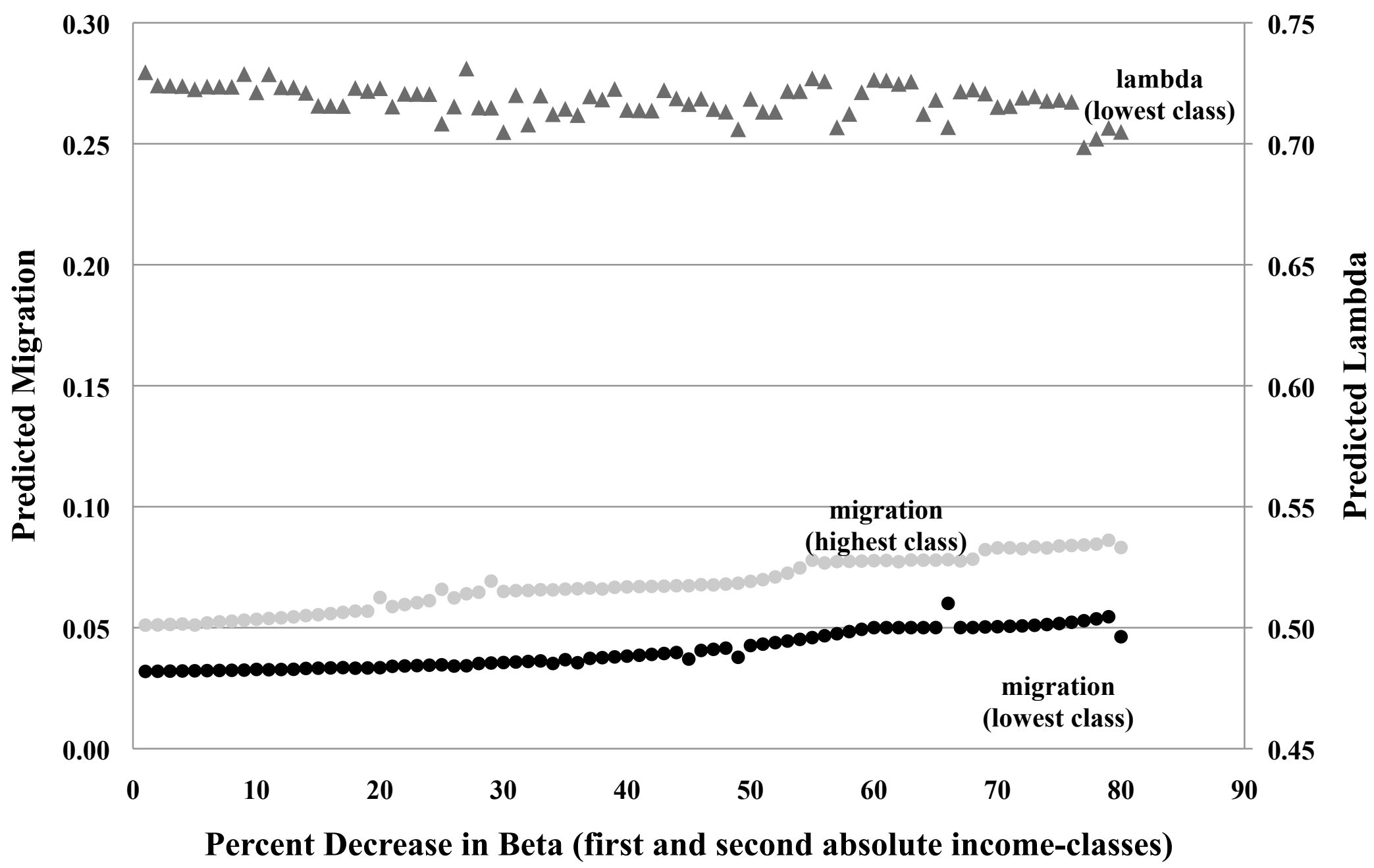

